\title{
Organization and Plasticity of Sodium Channel Expression in the Mouse Olfactory and Vomeronasal Epithelia
}

\author{
Florian Bolz, Stephanie Kasper ${ }^{\dagger}$, Bernd Bufe, Frank Zufall and Martina Pyrski * \\ Center for Integrative Physiology and Molecular Medicine, Saarland University, Homburg, Germany
}

To understand the molecular basis of neuronal excitation in the mammalian olfactory system, we conducted a systematic analysis of the organization of voltage-gated sodium $\left(\mathrm{Na}_{\mathrm{v}}\right)$ channel subunits in the main olfactory epithelium (MOE) and vomeronasal organ (VNO) of adult mice. We also analyzed changes in $\mathrm{Na}_{\mathrm{v}}$ channel expression during development in these two systems and during regeneration of the MOE. Quantitative PCR shows that $\mathrm{Na}_{v} 1.7$ is the predominant isoform in both adult MOE and VNO. We detected pronounced immunoreactivity for $\mathrm{Na}_{v} 1.7$ and $\mathrm{Na}_{v} 1.3$ in axons of olfactory and vomeronasal sensory neurons (VSNs). Analysis of $\mathrm{Na}_{v} 1.2$ and $\mathrm{Na}_{v} 1.6$ revealed an unexpected subsystem-specific distribution. In the MOE, these $\mathrm{Na}_{v}$ channels are

\section{OPEN ACCESS}

Edited by: Livio Oboti, Children's National Health System,

Reviewed by: Angelika Lampert, Uniklinik RWTH Aachen, Germany Anna Boccaccio, Consiglio Nazionale Delle Ricerche (CNR), Italy

${ }^{*}$ Correspondence: Martina Pyrski martina.pyrski@uks.eu

${ }^{\dagger}$ Present address: Stephanie Kasper, Laboratory for Muscle Plasticity, Department of Orthopedics, University of Zurich, Balgrist Campus, Zurich, Switzerland

Received: 03 February 2017 Accepted: 20 March 2017 Published: 03 April 2017

Citation:

Bolz F, Kasper S, Bufe B, Zufall F and Pyrski M (2017) Organization and Plasticity of Sodium Channel Expression in the Mouse Olfactory and Vomeronasal Epithelia.

Front. Neuroanat. 11:28. doi: 10.3389/fnana.2017.00028 absent from olfactory sensory neurons (OSNs) but present in non-neuronal olfactory cell types. In the VNO, $\mathrm{Na}_{v} 1.2$ and $\mathrm{Na}_{v} 1.6$ are confined to VSNs, with $\mathrm{Na}_{v} 1.2-$ immunoreactive somata solely present in the basal layer of the VNO. The subcellular localization of $\mathrm{Na}_{v} 1.3$ and $\mathrm{Na}_{v} 1.7$ in OSNs can change dramatically during periods of heightened plasticity in the MOE. During the first weeks of development and during regeneration of the olfactory epithelium following chemical lesion, expression of $\mathrm{Na}_{v} 1.3$ and $\mathrm{Na}_{v} 1.7$ is transiently enhanced in the somata of mature OSNs. Our results demonstrate a highly complex organization of $\mathrm{Na}_{\mathrm{v}}$ channel expression in the mouse olfactory system, with specific commonalities but also differences between the MOE and the VNO. On the basis of their subcellular localization, $\mathrm{Na}_{\mathrm{V}} 1.3$ and $\mathrm{Na}_{v} 1.7$ should play major roles in action potential propagation in both MOE and VNO, whereas $\mathrm{Na}_{v} 1.2$ and $\mathrm{Na}_{v} 1.6$ are specific to the function of VSNs. The plasticity of $\mathrm{Na}_{v}$ channel expression in OSNs during early development and recovery from injury could reflect important physiological requirements in a variety of activity-dependent mechanisms.

Keywords: voltage-gated sodium channels, olfactory epithelium, vomeronasal organ, development, regeneration

\section{INTRODUCTION}

Olfactory information processing and olfactory performance relies on the detection and transmission of peripheral olfactory information to the brain. This process begins within specialized bipolar neurons, the olfactory sensory neurons (OSNs), located in the main olfactory epithelium (MOE). The cilia and distal dendrites of an OSN perform the primary chemo-electrical signal transduction process to generate graded receptor potentials in response to odor detection 
(Firestein, 2001; Kleene, 2008; Pifferi et al., 2010). These electrical signals at the input level of an OSN are subsequently transformed into action potential sequences passing along the OSN axons to the olfactory bulb of the forebrain. In the glomerular neuropil of the olfactory bulb, OSN axon terminals synapse onto second order neurons, the mitral and tufted cells that convey olfactory information to higher brain centers (Shepherd et al., 2004; Wachowiak and Shipley, 2006). During the past 25 years, we have obtained detailed information on the molecular mechanisms underlying primary olfactory signal transduction in mammalian OSNs, but very little is still known about the molecular details underlying the initiation and propagation of action potentials in these sensory neurons. A comprehensive analysis of the function of voltage-activated ion channels in OSNs, specifically the voltage-activated sodium $\left(\mathrm{Na}_{\mathrm{v}}\right)$ channels, will be required for a molecular basis of neuronal excitation in the mammalian olfactory system, and for understanding the causes of heritable disorders underlying olfactory dysfunction in humans.

The sodium channel $\mathrm{Na}_{\mathrm{v}} 1.7$ (encoded by the gene $\mathrm{Scn} 9 a$ ) plays an essential role in mammalian olfaction: loss-of-function mutations in this gene cause a loss of the sense of smell (congenital general anosmia) in both mice and humans (Weiss et al., 2011). However, $\mathrm{Na}_{\mathrm{v}} 1.7$-deficient mouse OSNs can still generate action potentials in response to odorants, although the cells fail to propagate a signal to the target neurons in the olfactory bulb (Weiss et al., 2011). Therefore, we reasoned that other $\mathrm{Na}_{\mathrm{v}}$ channel isoforms must ultimately play additional roles in OSN excitation. Nine structurally related $\mathrm{Na}_{\mathrm{v}}$ channel $\alpha$-subunits $\left(\mathrm{Na}_{\mathrm{v}} 1.1-\mathrm{Na}_{\mathrm{v}} 1.9\right.$; Goldin et al., 2000; Catterall et al., 2005) are known to exist in mammals and differ in their tissue specificity, biophysical properties, and temporal expression during development and regeneration (Waxman et al., 1994; Kim et al., 2002; Dib-Hajj et al., 2010). Consistent with the cellular and behavioral phenotypes of mice harboring a conditional knockout mutation in Scn9a (Weiss et al., 2011), several additional investigations have provided evidence that $\mathrm{Na}_{\mathrm{v}} 1.7$ is not the only sodium channel expressed in the peripheral olfactory system, but that other isoforms are also present and could perform specific roles in excitation. In the MOE, several different $\mathrm{Na}_{\mathrm{v}}$ isoforms have been identified in mouse OSNs by expression profiling (Sammeta et al., 2007), RT-PCR (Ahn et al., 2011; Weiss et al., 2011; Frenz et al., 2014), and deep RNA sequencing (Ibarra-Soria et al., 2014). Only recently, $\mathrm{Na}_{\mathrm{v}} 1.7, \mathrm{Na}_{\mathrm{v}} 1.3$ (Weiss et al., 2011), and $\mathrm{Na}_{\mathrm{v}} 1.5$ (Frenz et al., 2014) were identified in mouse OSNs in addition to $\mathrm{Na}_{\mathrm{v}} 1.7$ in rat OSNs (Ahn et al., 2011) using immunohistochemistry. In the vomeronasal organ (VNO), very little information is available on $\mathrm{Na}_{\mathrm{V}}$ channel expression in vomeronasal sensory neurons (VSNs). Although multiple isoforms have been identified by RT-PCR (Fieni et al., 2003) and deep RNA sequencing (Ibarra-Soria et al., 2014), only a single study (Rupasinghe et al., 2012) localized $\mathrm{Na}_{\mathrm{v}} 1.7$ protein to the nerve and glomerular layers of the accessory olfactory bulb. What is still missing, however, is a systematic analysis of the organization of multiple $\mathrm{Na}_{\mathrm{v}}$ channel subunits in olfactory peripheral tissues. Such investigations are also required to address the critical question whether sensory neurons of the two major olfactory organs in mice-OSNs in the MOE and VSNs in the VNO-each may have evolved distinct mechanisms for neuronal excitation, or whether they employ the same $\mathrm{Na}_{\mathrm{v}}$ channels for action potential generation and conduction despite the fact these olfactory subsystems have evolved strikingly distinct mechanisms for primary signal transduction (Munger et al., 2009; Zufall and Munger, 2016).

Here, we analyze the cellular and subcellular distribution of different $\mathrm{Na}_{\mathrm{v}}$ channel subtypes in the peripheral olfactory system of mice during adulthood and development (MOE and $\mathrm{VNO}$ ), and during regeneration following chemical lesions (MOE). Our results show that $\mathrm{Na}_{\mathrm{v}} 1.7$ is the most abundant subtype not only in the MOE but also in the VNO. Furthermore, our immunohistochemical evidence suggests that both olfactory subsystems may employ $\mathrm{Na}_{\mathrm{v}} 1.3$ and $\mathrm{Na}_{\mathrm{v}} 1.7$ for axonal propagation of action potentials. We also find that these two channels likely play a major role in the developing MOE as they undergo specific changes in subcellular localization in OSNs during the first weeks of life. Finally, we demonstrate that $\mathrm{Na}_{\mathrm{v}} 1.2$ and $\mathrm{Na}_{\mathrm{v}} 1.6$ locate specifically to subpopulations of sensory neurons in the VNO.

\section{MATERIALS AND METHODS}

\section{Animals}

All procedures were approved by the Institutional Animal Care and Use Committee of Saarland University and were in full accordance with the laws for animal experiments of the German government. Experiments were performed on mouse tissues derived from mice at different ages and of both sexes. For the developmental study, we used mice at embryonic day 18 (E18), postnatal day 2 (P2), P7, P14 and P21. Results from adult mice were obtained at 6-8 weeks of age. Ages of mice used for the regeneration study are as specified in "Triton X Lesioning of the Main Olfactory Epithelium" Section. We used wild type mice (C57BL/6J, denoted as $\mathrm{B} 6$ ), $\mathrm{cNa}_{\mathrm{v}} 1.7$ mice (Weiss et al., 2011) and OMP-GFP ${ }^{+/-}$mice (B6; 129P2-Omp ${ }^{\text {tm } 3 \text { Mom }} /$ MomJ, The Jackson Laboratory; stock\# 006667), heterozygous for both OMP (olfactory marker protein) and GFP (green fluorescent protein; Potter et al., 2001). Mice were housed in micro-isolator cages on a 12:12-h light/dark cycle with water and food available ad libitum.

\section{RNA Extraction and Quantitative Real Time RT-PCR}

Olfactory mucosa and VNO were obtained from 6 to 8week old B6 mice. Total RNA was isolated using the InnuPREP RNA isolation kit (Analytik Jena). Quality was assessed by gel electrophoresis and photometric measurements. cDNA was synthesized from $0.5 \mu \mathrm{g}$ of total RNA using the Smart cDNA Synthesis Kit (Clontech) and Superscript II reverse transcriptase (Invitrogen). Quantitative PCR for the different mouse $\mathrm{Na}_{\mathrm{v}}$ subunits was done on a My-iQ-cycler (Bio-Rad) using $\mathrm{iQ}^{\mathrm{TM}}$ SYBR $^{\circledR}$ Green Supermix (Bio-Rad) according to the manufacturers' recommendations. Forward 
and reverse gene specific primers used were $\mathrm{Na}_{\mathrm{v}} 1.1$ (AGCCTG GTAGAACTTGGCCTTGC and TGCCAACCACGGCAAAAA TAAAG), $\mathrm{Na}_{\mathrm{v}} 1.2$ (TGGGATCTTCACCGCAGAAATG and TG GGCCAGGATTTTGCCAAC), $\mathrm{Na}_{\mathrm{v}} 1.3$ (AGCTTGGCCTGGC AAACGTG and ATGCCGACCACGGCAAAAATG), $\mathrm{Na}_{\mathrm{v}} 1.5$ (ACAGCCGAGTTTGAGGAGATGC and CGCTGATTCGGT GCCTCA), $\mathrm{Na}_{\mathrm{v}} 1.6$ (ACGCCACAATTCGAACATGTCC and CCTGGCTGATCTTACAGACGCA), $\mathrm{Na}_{\mathrm{v}} 1.7$ (ACGGATGAAT TCAAAAATGTACTTGCAG and GTTCTCGTTGATCTTGCA AACACA). PCR conditions were: $95^{\circ} \mathrm{C}$ for $3 \mathrm{~min}$ initial denaturation, followed by 42 cycles of $95^{\circ} \mathrm{C}$ for $30 \mathrm{~s}, 64^{\circ} \mathrm{C}$ for $20 \mathrm{~s}$, $72^{\circ} \mathrm{C}$ for $30 \mathrm{~s}$. Triplicate reactions were performed on 96-well plates and analyzed with the iQ5 Software (Bio-Rad). Quality controls for PCR conditions, linearity of the amplification reaction and RNA isolation were assessed according to MIQE guidelines (Bustin et al., 2009). In addition, the specificity of PCR products was confirmed by gel electrophoresis and by direct DNA sequencing of the PCR products. For copy number calculation calibration curves for each primer set with defined amounts of start copies diluted in tRNA containing reaction buffer were used.

\section{Olfactory Tissue Preparation}

Perfusion of mice and tissue preparation followed previously described methods (Weiss et al., 2011). In brief, mice were sacrificed by anesthesia $(165 \mathrm{mg} / \mathrm{kg}$ body weight ketamine (Pharmacia GmbH, Berlin, Germany) and $11 \mathrm{mg} / \mathrm{kg}$ body weight xylazine (Bayer Health Care, Leverkusen, Germany)) and subjected to transcardial perfusion using phosphate buffered saline (PBS) followed by perfusion with $4 \%(\mathrm{w} / \mathrm{v})$ paraformaldehyde in PBS as fixative. Two day-old mice and mice at embryonic day 18 (E18) were decapitated and fixated by immersion in 4\% PFA for $24 \mathrm{~h}$ instead of transcardial perfusion. E18 embryos were dissected from anesthetized, time-pregnant females. Following fixation, olfactory tissues were incubated in $30 \%$ sucrose in PBS at $4^{\circ} \mathrm{C}$ for 2 days, embedded in O.C.T. (Tissue-Tek), and snap-frozen in a dry ice/2-methylbutane bath. Frozen tissue sections $(12 \mu \mathrm{m})$ were collected on a cryostat (HM525; Microm, Walldorf, Germany), thaw-mounted onto glass slides (Superfrost Plus, Polysciences), and stored at $-80^{\circ} \mathrm{C}$.

\section{Triton X Lesioning of the Main Olfactory Epithelium}

For peripheral deafferentation, young adult OMP-GFP mice or B6 mice (6-8 weeks) received unilateral intranasal irrigation with $100 \mu \mathrm{l}$ of a $0.7 \%$ Triton X-100 solution prepared in phosphate-buffered saline (PBS), $\mathrm{pH}$ 7.4. Mice were two-hand scruff restrained to prevent head movement to inject $100 \mu \mathrm{l}$ solution into the left nasal cavity using a 21-gauche, blunt-end needle (Braun, Melsungen) attached to a $1 \mathrm{ml}$ syringe. Following intranasal treatment, mice were monitored to ensure complete recovery and allowed to survive for $1,2,4,6,8$ and 10 weeks ( $n=2$ mice each) before subjected to transcardial perfusion and olfactory tissue preparation as detailed above.

\section{Immunohistochemistry}

All procedures were conducted at room temperature $\left(20^{\circ} \mathrm{C}\right)$, only incubation of tissue sections with primary antibodies was at $4^{\circ} \mathrm{C}$. The following primary antibodies and control peptides were used: $\mathrm{Na}_{\mathrm{v}} 1.2$ (1:500, rabbit polyclonal AB5206, control peptide ASAESRDFSGAGGIGVFSE, Millipore), $\mathrm{Na}_{\mathrm{v}} 1.3$ (1:500, rabbit polyclonal AB5208, control peptide HLEGNHRADGDRFP, Millipore) or $\mathrm{Na}_{\mathrm{v}} 1.3$ (1:500, goat polyclonal sc-22202, St. Cruz), $\mathrm{Na}_{\mathrm{v}} 1.6$ (1:500, rabbit polyclonal ASC-009, control peptide CIANHTGVDIHRNGDFQKNG, Alomone), $\mathrm{Na}_{\mathrm{v}} 1.7$ (1:500, rabbit polyclonal AB5390, control peptide EFTSIGRSRIMGLSE, Millipore), OMP (1:3000, goat polyclonal; gift of F. Margolis, University of Maryland, Baltimore, MD, USA), V2R2 (1:5000, rabbit polyclonal; provided by R. Tirindelli, University of Parma, Parma, Italy), GAP43 (1:2000, mouse monoclonal MAP347, Millipore).

Expression of $\mathrm{Na}_{\mathrm{v}}$ channel isoforms was detected by tyramid signal amplification according to the manufacturer's protocol (TSA-Biotin System, Perkin Elmer). In brief, coronal cryosections $(12-14 \mu \mathrm{m})$ of the VNO and MOE were brought to room temperature, rinsed in TN-buffer (100 mM Tris, $150 \mathrm{mM} \mathrm{NaCl}, \mathrm{pH} 7.5$ ), incubated in $3 \% \mathrm{H}_{2} \mathrm{O}_{2}$ for $10 \mathrm{~min}$, washed in TN-buffer, and incubated for $2 \mathrm{~h}$ in blocking solution containing 4\% normal horse serum (Vector Laboratories) and $0.3 \%$ Triton X-100 (Sigma) prepared in TN. Then, sections were sequentially incubated in primary antibody diluted in blocking solution for $18-24 \mathrm{~h}$, in biotinylated donkeyanti-rabbit antibody (1:400, \#711-065-152, Jackson Immuno Research) or in biotinylated horse-anti-goat antibody (1:400, BA-9500, Vector Laboratories) for $1 \mathrm{~h}$, in streptavidin-HRP (1:100, TSA-Biotin System, Perkin Elmer) for $30 \mathrm{~min}$, in biotinylated tryamid (1:100, TSA-Biotin System, Perkin Elmer) for $10 \mathrm{~min}$, and in Alexa 546-conjugated streptavidin (1:200; S-11225, Invitrogen) or in Alexa 633-conjugated streptavidin (1:200; S-21375 Invitrogen). Nuclei were counterstained with Hoechst 33342 nuclear dye (Invitrogen, 1:10,000) for $10 \mathrm{~min}$ and sections were cover slipped in fluorescence mounting medium (DAKO). For the colocalization of $\mathrm{Na}_{\mathrm{v}} 1.7$ with $\mathrm{Na}_{\mathrm{v}} 1.3$, we performed two sequential TSA amplifications using the $\mathrm{Na}_{\mathrm{v}} 1.7$ antibody made in rabbit followed by the $\mathrm{Na}_{\mathrm{v}} 1.3$ antibody made in goat using the appropriate biotinylated secondary antibodies (see above). In between the two TSA protocols Biotin blocking was performed using the Avidin/Biotin blocking kit (Vector Laboratories). GAP43, OMP and V2R2 were detected by indirect immunofluorescence after TSA-amplification of $\mathrm{Na}_{\mathrm{V}}$ channels using the secondary antibodies Alexa-Fluor 488 conjugated donkey-anti-goat or Alexa-Fluor 647 conjugated donkey-anti-mouse (all 1:1000, Invitrogen). For V2R2 detection, unbound rabbit IgG epitopes from the previous TSA protocol were blocked for $1 \mathrm{~h}$ with donkey-anti-rabbit Fab-fragments (1:50, Biomol, Rockland, ME, USA). The specificity of the immunostainings was verified by several types of control experiments: (i) omitting primary antibody; (ii) incubation peptide pre-adsorpt $\mathrm{Na}_{\mathrm{v}}$ antisera (5-fold excess of the cognate immunization peptide); and (iii) applying $\mathrm{Na}_{\mathrm{v}}$ antibodies to olfactory tissue derived from $\mathrm{cNa}_{\mathrm{v}} 1.7$ knockout mice (Weiss et al., 2011). 


\section{Microscopy and Image Assembly}

Fluorescence images were acquired on a BX61 epifluorescence microscope attached to a DP71 camera (Olympus) or on a LSM 710/ConfoCor-3 confocal microscope (Zeiss). Confocal images are Z-stacks presented as maximum intensity projections of 10-20 confocal sections, each $0.4 \mu \mathrm{m}$ thick. Images were assembled and minimally adjusted in contrast and brightness using Photoshop Elements 10 (Adobe Photoshop).

\section{RESULTS}

To understand the molecular basis of neuronal excitation in the mammalian olfactory system, we used a combination of quantitative real time RT-PCR (qPCR) and immunohistochemistry and analyzed the organization and plasticity of $\mathrm{Na}_{\mathrm{v}}$ channel $\alpha$-subunit expression in the peripheral olfactory system of mice. We focused on the MOE and the VNO which represent the two major sensory substructures of the mouse olfactory system (Munger et al., 2009). We describe the neural architecture and subcellular distribution of the major $\mathrm{Na}_{\mathrm{v}}$ channel subunits that we could identify in these sensory epithelia during adulthood and development of the MOE and VNO, and during regeneration of the MOE following chemical epithelial ablation.

\section{qPCR Reveals $\mathrm{Na}_{\mathrm{v}} 1.7$ as the Most Abundant $\mathrm{Na}_{\mathrm{v}}$ Channel in both MOE and VNO}

Sensory neurons of MOE and VNO employ distinct primary signal transduction mechanisms but it is unclear whether these two olfactory subsystems have also evolved distinct molecular mechanisms for action potential generation and propagation or whether they employ the same mechanisms. To assess this question, we first compared the expression profiles of different $\mathrm{Na}_{\mathrm{V}}$ isoforms in the two subsystems. We used total RNA preparations from MOE and VNO of wild type B6 mice and conducted qPCR analysis using gene-specific primers for six members of the $\mathrm{Na}_{\mathrm{v}}$ family: $\mathrm{Na}_{\mathrm{v}} 1.1$ (Scn1a), $\mathrm{Na}_{\mathrm{v}} 1.2$ (Scn2a), $\mathrm{Na}_{\mathrm{v}} 1.3$ (Scn3a), $\mathrm{Na}_{\mathrm{v}} 1.5$ (Scn5a), Na 1.6 (Scn8a), and $\mathrm{Na}_{\mathrm{v}} 1.7$ $(\operatorname{Scn} 9 a)$. Quantitative analyses revealed that overall relative abundances of the different $\mathrm{Na}_{\mathrm{v}}$ channel isoforms in whole MOE and VNO were surprisingly similar (Figure 1). In both tissues, mRNA encoding the $\mathrm{Na}_{\mathrm{v}} 1.7 \quad \alpha$-subunit represented by far the most abundant isoform. We also detected mRNA encoding the isoforms $\mathrm{Na}_{\mathrm{v}} 1.5, \mathrm{Na}_{\mathrm{v}} 1.3, \mathrm{Na}_{\mathrm{v}} 1.6, \mathrm{Na}_{\mathrm{v}} 1.2$ and $\mathrm{Na}_{\mathrm{v}} 1.1$ in both tissues (see legend of Figure 1 for mRNA copy numbers).

\section{In the MOE $\mathrm{Na}_{\mathrm{v}} 1.3$ and $\mathrm{Na}_{\mathrm{v}} 1.7$ Represent the Predominant $\mathrm{Na}_{\mathrm{v}}$ Channel Isoforms}

In addition to OSNs that mediate the sense of smell, the MOE encompasses non-neuronal supporting and microvillous cells, as well as dividing stem cells that form the olfactory mucosa (Farbman, 1992). To verify that the $\mathrm{Na}_{\mathrm{v}}$ isoforms we identified by qPCR localize to OSNs, we performed immunohistochemistry for the isoforms $\mathrm{Na}_{\mathrm{v}} 1.2, \mathrm{Na}_{\mathrm{v}} 1.3, \mathrm{Na}_{\mathrm{v}} 1.6$ and $\mathrm{Na}_{\mathrm{v}} 1.7$ in the MOE

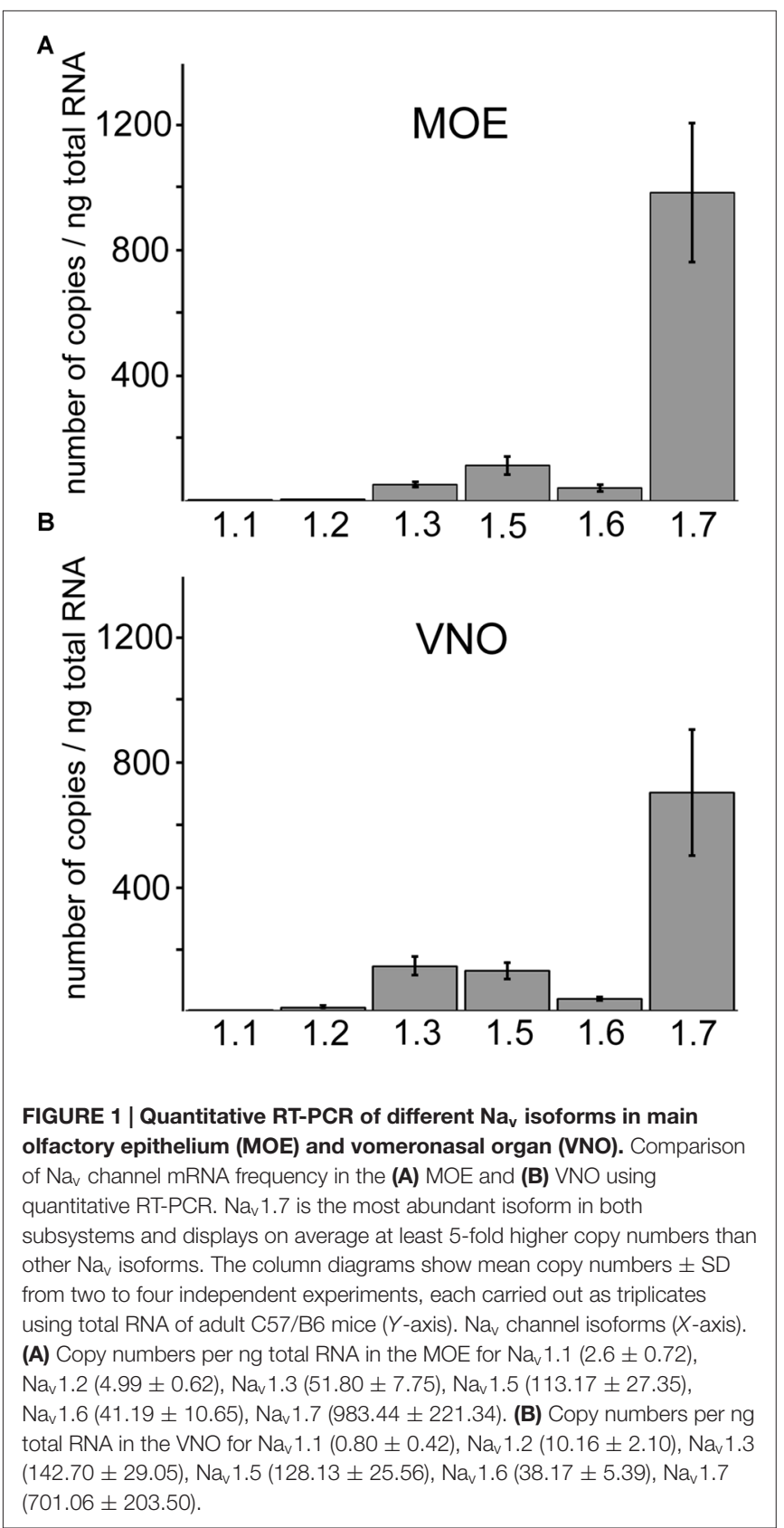

of adult mice (Figure 2) using previously established antibodies (Sage et al., 2007; Gao et al., 2009; Weiss et al., 2011). We did not investigate the distribution of $\mathrm{Na}_{\mathrm{v}} 1.5$ in OSNs as this has already been reported by Frenz et al. (2014). Olfactory tissue sections from B6 mice or from heterozygous OMP-GFP mice were subjected to immunohistochemistry using tyramid signal amplification. OMP-GFP mice express the reporter GFP (green fluorescence protein) under control of the promotor of OMP (olfactory marker protein). Thus, mature OSNs can be readily identified by their endogenous GFP fluorescence in these mice.

Of the four candidates analyzed in adult MOE, we identified robust immunostaining for $\mathrm{Na}_{\mathrm{v}} 1.3$ and $\mathrm{Na}_{\mathrm{v}} 1.7$ in 

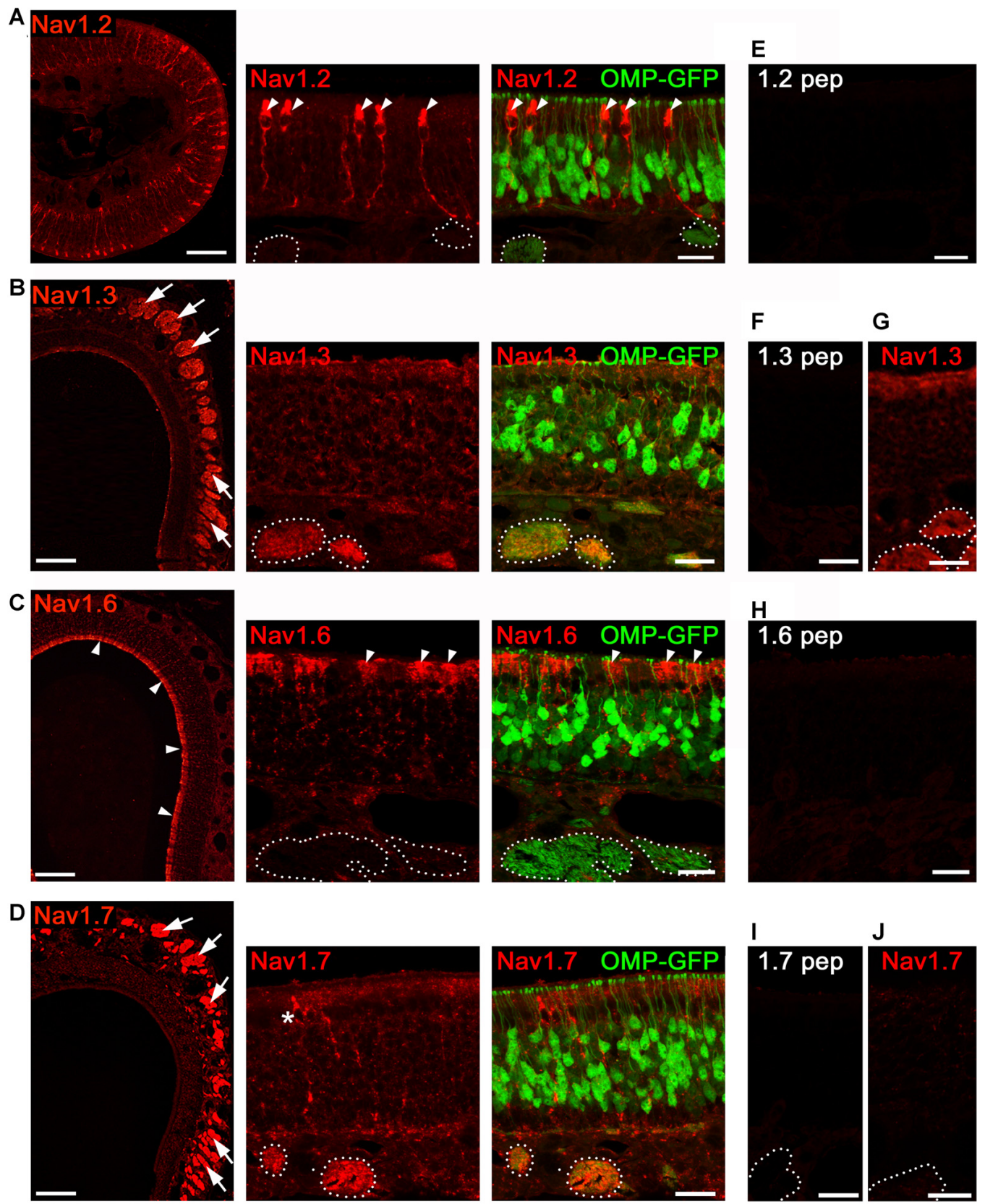

FIGURE 2 | Analysis of $\mathbf{N a}_{\mathbf{v}}$ channel expression in MOE of adult mice. Confocal images showing immunoreactivity (red) for (A) $\mathrm{Na}$ 1.2, (B) Na 1.3 , (C) $\mathrm{Na} v 1.6$, and (D) $\mathrm{Na}_{v}$ 1.7. We used coronal MOE cryosections (12 $\mu \mathrm{m}$ ) of adult OMP-GFP mice (left, overviews; right, magnifications). Endogenous GFP (green) is located to mature, OMP+ OSNs as shown in the magnifications at the right. (A) Nav 1.2 staining is restricted to microvillar cells (arrowheads) but absent from OSNs or axon bundles (dotted circles) identified by OMP-GFP labeling. (B) Robust Nav1.3 staining is present in axon bundles (arrows, left) that colocalize with OMP-GFP (dotted circles, right). (C) $\mathrm{Na}_{v} 1.6$ labeling of the MOE surface (left, arrow heads) corresponds to sustentacular cells (right). OSNs and axon bundles (dotted line) lack $\mathrm{Na}_{\mathrm{v}} 1.6$ staining. (D) Na 1.7 immunoreactivity is profound in axon bundles, and occasionally found in microvillar cells (asterisk). (E,F,H,I) Blocking peptide control experiments lack immunoreactivity. (G) $\mathrm{Na}_{\mathrm{v}} 1.3$ immunoreactivity is present in $\mathrm{CNa}_{\mathrm{v}} 1.7^{-/-}$mice. (J) $\mathrm{Na}_{\mathrm{v}} 1.7$ immunoreactivity is absent in cNa $1.7^{-/-}$mice. Images for each $\mathrm{Na}_{v}$ channel immunostaining are representatives of $n \geq 3$ mice and $n=20$ sections per mouse. Scale bars overviews $100 \mu \mathrm{m}$, and magnifications $20 \mu \mathrm{m}$.

OSN axon bundles (Figures 2B,D) located in the lamina propria underlying the MOE. Axon bundles were identified through endogenous GFP fluorescence in OMP-GFP mice (Figures 2B,D). OSN somata showed relatively little $\mathrm{Na}_{\mathrm{v}} 1.3$ and
$\mathrm{Na}_{\mathrm{v}} 1.7$ immunostaining which was homogenously distributed throughout the depth of the MOE. OSN dendrites or dendritic endings (knobs) lacked immunoreactivity altogether (for summary see Figure 7). 
By contrast, staining for $\mathrm{Na}_{\mathrm{v}} 1.2$ and $\mathrm{Na}_{\mathrm{v}} 1.6$ was absent from OSNs (Figures 2A,C), but we observed robust staining for $\mathrm{Na}_{\mathrm{v}} 1.2$ in a discrete population of non-neuronal microvillar cells (Figure 2A). These cells can be identified by their specific morphology including a club-shaped soma that is positioned in the most apical MOE layer, extending a thick process towards the basal membrane (Elsaesser and Paysan, 2005). Consistent with a previous report (Frenz et al., 2014), we also noticed a subset of MOE microvillar cells that were labeled for $\mathrm{Na}_{\mathrm{v}} 1.7$ (Figures 2B,D). We observed $\mathrm{Na}_{\mathrm{v}} 1.6$ immunoreactivity in the apical cytosol of sustentacular cells, a non-neuronal cell type of the MOE with glia-like supportive function (Farbman, 1992).

As controls for antibody specificity, we omitted primary antibodies to control binding of secondary antibodies to the tissue. We also conducted antibody blocking experiments by preincubation of each antiserum with its cognate immunization peptide. In all cases, reactions were devoid of any signal for the $\mathrm{Na}_{\mathrm{v}}$ channels investigated (Figures 2E,F,H,I). Furthermore, control experiments using tissue from $\mathrm{cNa}_{\mathrm{v}} 1.7^{-/-}$knockout mice, in which $\mathrm{Na}_{\mathrm{v}} 1.7$ has been deleted in all OMP-expressing cells (Weiss et al., 2011), lacked $\mathrm{Na}_{\mathrm{v}} 1.7$ immunoreactivity (Figure 2J). Moreover, immunoreactivity for $\mathrm{Na}_{\mathrm{v}} 1.3$ was not affected by the $\mathrm{Na}_{\mathrm{v}} 1.7$ deletion and we observed prominent $\mathrm{Na}_{\mathrm{v}} 1.3$ staining in axon bundles of $\mathrm{cNa}_{\mathrm{v}} 1.7^{-/-}$mice (Figure 2G).

\section{$\mathrm{Na}_{\mathrm{v}} 1.2$ and $\mathrm{Na}_{\mathrm{v}} 1.6$ Localize to VSN Somata in the VNO}

In the VNO, our qPCR experiments suggested that $\mathrm{Na}_{\mathrm{v}} 1.7$ is not the sole $\mathrm{Na}_{\mathrm{v}}$ channel (Figure 1B). By performing immunohistochemistry analyses in VNO tissue sections from adult mice, we localized all four channel candidates $-\mathrm{Na}_{\mathrm{v}} 1.2$, $\mathrm{Na}_{\mathrm{v}} 1.3, \mathrm{Na}_{\mathrm{v}} 1.6$, and $\mathrm{Na}_{\mathrm{v}} 1.7$ - to VSNs (for summary see Figure 7). Interestingly, we observed profound $\mathrm{Na}_{\mathrm{v}} 1.2$ staining in VSNs residing in the basal VNO layer (Figure 3A). Colocalization with an antibody against the vomeronasal receptor V2R2, specific for family C V2Rs that show expression in almost all basal VSNs (Martini et al., 2001), confirmed the confinement of $\mathrm{Na}_{\mathrm{v}} 1.2$ to basal VSNs (Figure 3A).

$\mathrm{Na}_{\mathrm{v}} 1.2$ labeling appeared to be primarily restricted to VSN somata, dendrites, and dendritic knobs (Figure $\mathbf{3 A}$ ) as we did not detect $\mathrm{Na}_{\mathrm{v}} 1.2$ in VSN axon bundles leaving the VNO and forming the vomeronasal nerves (Figure 3A). Surprisingly, we observed a similar subcellular distribution for $\mathrm{Na}_{\mathrm{v}} 1.6$ that showed strong immunoreactivity in VSN somata and knobs whereas axon bundles were devoid of any staining (Figure 3C). In contrast to $\mathrm{Na}_{\mathrm{v}} 1.2$, we detected $\mathrm{Na}_{\mathrm{v}} 1.6$ staining in VSNs of both apical and basal VNO layers. This was confirmed in the VNO of OMP-GFP mice in which virtually all $\mathrm{GFP}^{+} \mathrm{VSN}$ somata were also labeled for $\mathrm{Na}_{\mathrm{v}} 1.6$ (Figure 3C). However, the signal intensity for $\mathrm{Na}_{\mathrm{V}} 1.6$ in basal VSNs appeared stronger than that in apical VSNs. The subcellular localization of the two channel subtypes $\mathrm{Na}_{\mathrm{v}} 1.2$ and $\mathrm{Na}_{\mathrm{v}} 1.6$ to VSN somata makes them ideal candidates involved in the generation of action potentials in VSNs.

\section{$\mathrm{Na}_{\mathrm{v}} 1.3$ and $\mathrm{Na}_{\mathrm{v}} 1.7$ Localize to VSN Axons}

Next, we analyzed the distribution of $\mathrm{Na}_{\mathrm{v}} 1.3$ and $\mathrm{Na}_{\mathrm{v}} 1.7$ in the adult vomeronasal sensory epithelium. We detected robust immunoreactivity for both channel subtypes in axon bundles forming the vomeronasal nerves, situated in the dorsomedial aspect of the VNO (Figures 3B,D). Furthermore, we found moderate $\mathrm{Na}_{\mathrm{v}} 1.3$ staining in VSN dendrites and dendritic knobs as well as in VSN somata (Figure 3B). For $\mathrm{Na}_{\mathrm{v}} 1.7$, in addition to the striking labeling of axon bundles, we observed substantial staining in VSN dendritic knobs whereas immunoreactivity was rather weak in VSN somata and dendrites (Figure 3D). VSN somata stained for $\mathrm{Na}_{\mathrm{v}} 1.3$ and $\mathrm{Na}_{\mathrm{v}} 1.7$ were present throughout the depth of the vomeronasal sensory epithelium.

As a control, we analyzed the VNO from $\mathrm{cNa}_{\mathrm{v}} 1.7^{-/-}$ mice in which $\mathrm{Na}_{\mathrm{v}} 1.7$ has been conditionally deleted in all OMP-expressing cells including all VSNs (Weiss et al., 2011). Consistent with our results in the MOE, $\mathrm{cNa}_{\mathrm{v}} 1.7^{-/-}$ mice lacked $\mathrm{Na}_{\mathrm{v}} 1.7$ staining in the VNO (Figure $3 \mathrm{H}$ ). Furthermore, immunoreactivity was absent when omitting primary antibodies (not shown), as well as in peptide control reactions (Figures 3E-G).

Taken together, the results depicted in Figure 3 reveal characteristic, differential expression in distinct VSN compartments for the four $\mathrm{Na}_{\mathrm{v}}$ channel subtypes investigated. $\mathrm{Na}_{\mathrm{v}} 1.2$ and $\mathrm{Na}_{\mathrm{v}} 1.6$ are predominantly expressed in VSN cell bodies. $\mathrm{Na}_{\mathrm{v}} 1.3$ and $\mathrm{Na}_{\mathrm{v}} 1.7$ are mainly, but not exclusively, expressed in VSN axons. $\mathrm{Na}_{\mathrm{v}} 1.2$ constitutes a novel marker for VSNs of the basal layer of the vomeronasal sensory epithelium and we predict it to play a specific function in these neurons.

\section{$\mathrm{Na}_{\mathrm{v}}$ Channel Expression during Early Postnatal VNO Development}

Changes in the subcellular distribution of $\mathrm{Na}_{\mathrm{v}}$ channels during development could impact on the electrical activity and generation of nerve impulses produced by VSNs and OSNs during this time. We investigated the localization of the four $\mathrm{Na}_{\mathrm{v}}$ channels at different developmental time points using immunohistochemistry, focusing first on the VNO. We analyzed VNO tissue sections derived from B6 or OMP-GFP mice on tissue sections of mice at postnatal day 2 (P2), P7, and P14 (Figures 3I-L). We found $\mathrm{Na}_{\mathrm{v}} 1.2$ and $\mathrm{Na}_{\mathrm{v}} 1.6$ immunoreactivity in VSN somata starting at P2 with increasing numbers of labeled neurons towards P14 (Figures 3I,K). Axon bundles were devoid of any staining in both cases. As seen in adult mice (Figure 3A), restriction of $\mathrm{Na}_{\mathrm{v}} 1.2$ stained somata to the basal VNO layer was already prominent at P7 (Figure 3I). $\mathrm{Na}_{\mathrm{v}} 1.6$ labeled somata, however, were found at all depths of the vomeronasal epithelium at P7 (Figure 3K), closely resembling the distribution in the adult VNO. Substantial $\mathrm{Na}_{\mathrm{v}} 1.7$ staining of individual VSN somata, knobs, and axon bundles was detectable at P2 (Figure 3L), while $\mathrm{Na}_{\mathrm{V}} 1.3$ staining in these compartments became evident at P7 (Figure 3J), with numbers of labeled VSNs increasing towards P14. 


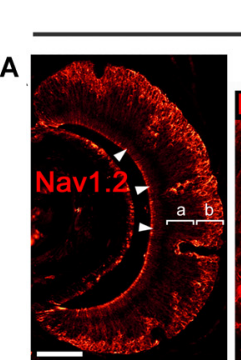

adult

$\mathbf{B}$
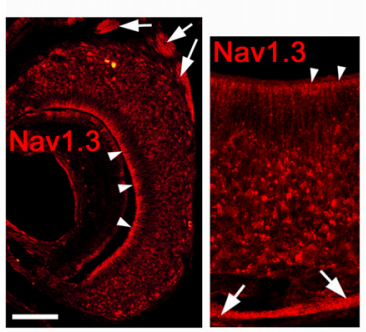

C
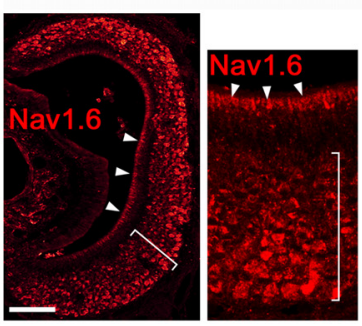

D
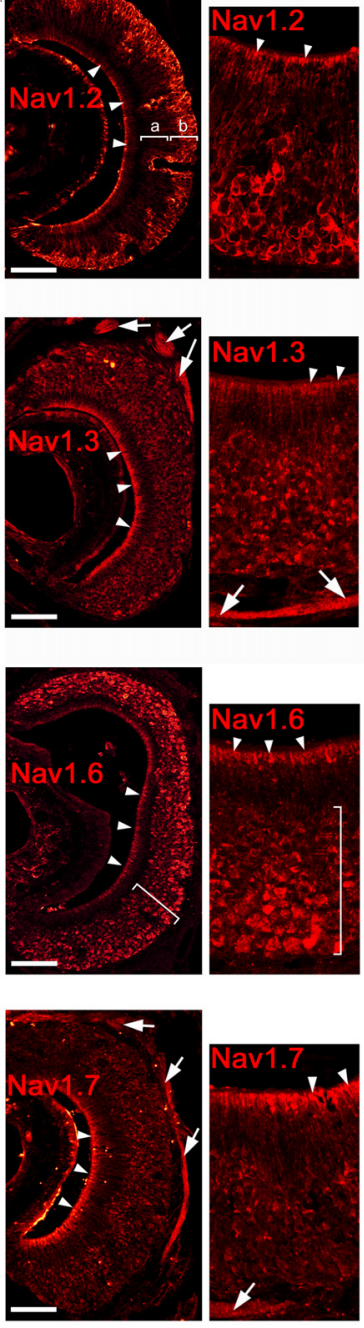
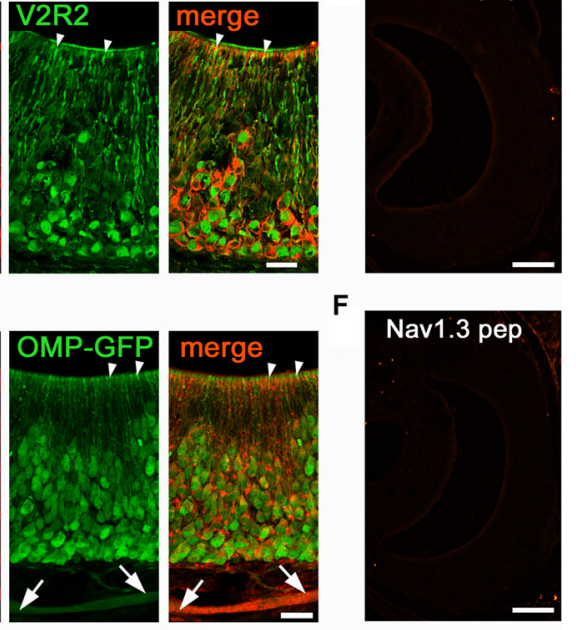

G
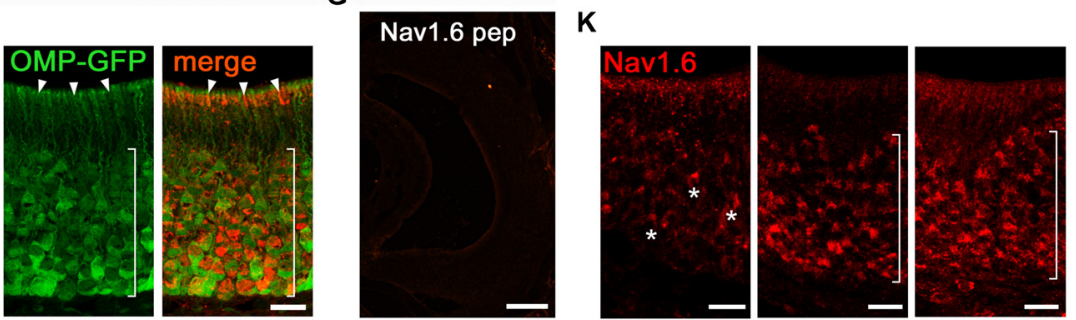

$\mathbf{H}$
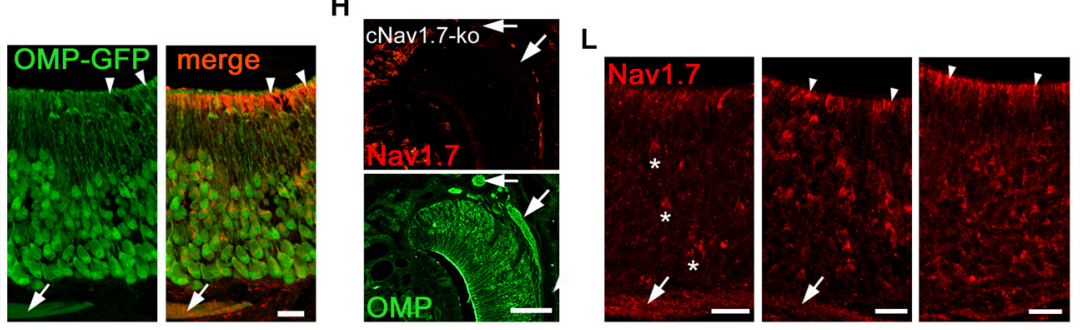

FIGURE 3 | Analysis of $\mathbf{N a}_{\mathbf{v}}$ channel expression in VNO of adult and early postnatal mice. (A-H) Confocal images showing immunoreactivity (red) observed for (A) $\mathrm{Na}_{v} 1.2$, (B) $\mathrm{Na}_{v} 1.3$, (C) $\mathrm{Na}_{v} 1.6$, and (D) $\mathrm{Na}_{v} 1.7$ in $12 \mu \mathrm{m}$ coronal VNO cryosections of adult mice (left, overviews; right, magnifications). (A) Na 1.2 staining is present in VSN knobs (arrowheads), dendrites and somata of basal (b) VSNs but absent in apical (a) VSNs (overview left). The magnification at the right shows colocalization of $\mathrm{Na}_{\mathrm{v}} 1.2$ with V2R2 (green). (B) Nav 1.3 staining is moderate in VSN knobs (arrowheads), dendrites and somata and robust in axon bundles as identified in OMP-GFP mice (green signal). (C) Nav 1.6 is strong in knobs (arrowheads) and somata (bracket). The magnification and colocalization with OMP-GFP shows a decline in $\mathrm{Na}_{v} 1.6$ intensity from basal to apical. (D) Nav1.7 staining is prominent in VSN knobs (arrowheads) and axon bundles (arrows). Peptide control experiments (E,F,G) lack immunoreactivity. (H) Nav1.7 staining (top) is absent in axon bundles (arrows) of $\mathrm{cNa} \mathrm{v}_{\mathrm{v}} 1.7^{-/-}$mice, visualized by OMP staining (bottom). (I-L) Immunoreactivity (red) for (I) $\mathrm{Na}_{v} 1.2$, (J) Na 1.3 , (K) Nav 1.6, and (L) $\mathrm{Na}_{v} 1.7$ at postnatal (P) day 2, P7, and P14. (I) Onset of Na 1.2 in P2 VSNs (asterisks). At P7 and P14, basal (b) confinement of $\mathrm{Na}_{\mathrm{v}} 1.2$ somata and labeled knobs (arrowheads; a). (J) $\mathrm{Na}_{\mathfrak{v}} 1.3$ is visible in single somata (asterisks) and axon bundles (arrows) at P7, and shows diffuse staining of the apical VNO (arrowheads) starting at P2. (K) Onset of $\mathrm{Na}_{\mathrm{v}} 1.6$ in somata (asterisks) at P2 with increasing numbers at P7 and P14 throughout the VNO (brackets). (L) Na 1.7 in single VSN somata (asterisks) and axon bundles (arrows) starts at P2. The knob area is substantially stained from P7 onwards. Images are representatives of $n \geq 3$ adult mice $(n=20$ sections per mouse) and $n=2$ juvenile mice each at P2, P7, and P14 ( $n \geq 10$ sections per mouse). Scale bars overviews (A-H, left) and (E-H) $100 \mu \mathrm{m}$; magnifications (A-D) and (I-L) $20 \mu \mathrm{m}$.

Thus, $\mathrm{Na}_{\mathrm{v}}$ channel expression in the developing $\mathrm{VNO}$ is detectable in VSNs shortly after birth, increases with age, and the particular cellular and subcellular distribution pattern of each channel type is formed during the first 2 weeks of postnatal development.

\section{The Subcellular Distribution of $\mathrm{Na}_{\mathrm{v}} 1.3$ and $\mathrm{Na}_{\mathbf{v}} 1.7$ in OSNs is Developmentally Regulated}

We then investigated the localization of $\mathrm{Na}_{\mathrm{v}} 1.3$ and $\mathrm{Na}_{\mathrm{v}} 1.7$ at different developmental time points in the MOE using 
A

C
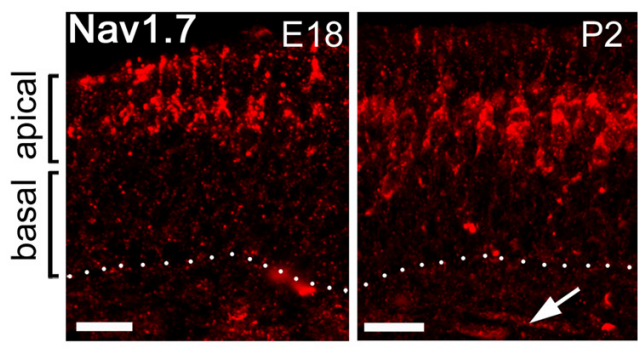

2
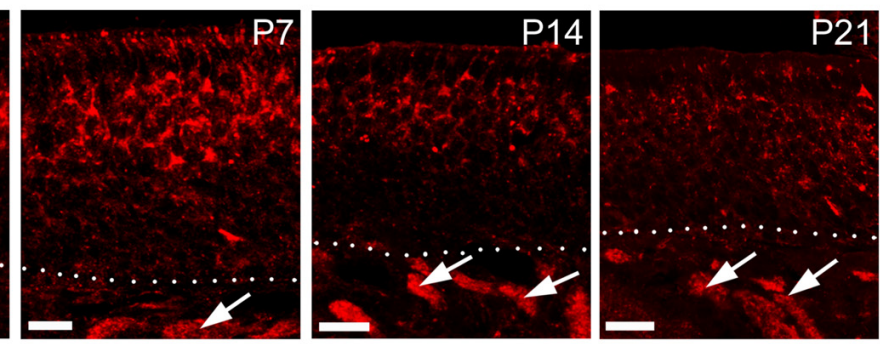

D
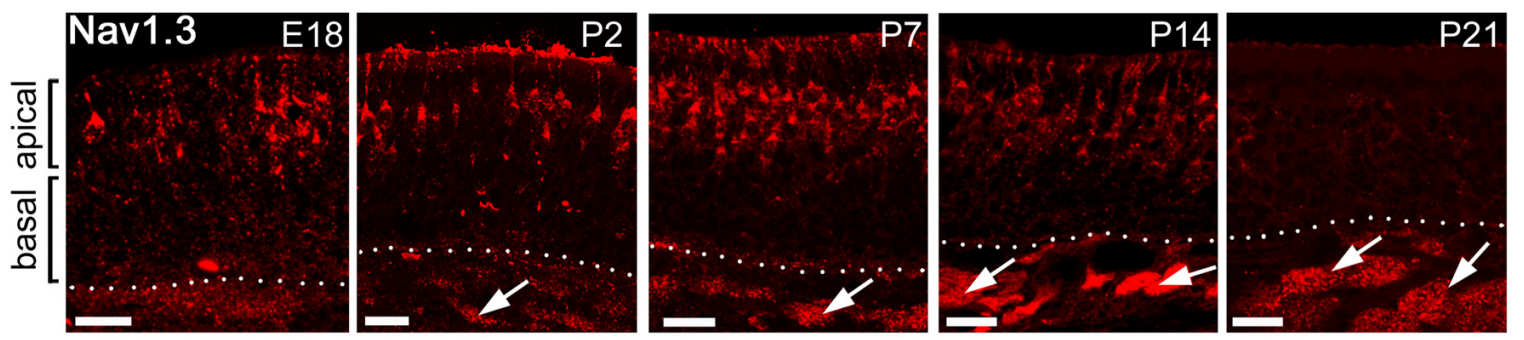

FIGURE 4 | Subcellular localization of $\mathrm{Na}_{\mathbf{v}} \mathbf{1 . 7}$ and $\mathrm{Na}_{\mathbf{v}} \mathbf{1 . 3}$ staining during mouse MOE development. (A,B) Coronal tissue sections showing the dorsal aspect of the left nasal cavity (septum to the left) of a postnatal day 7 (P7) mouse. A strip of strong immunoreactivity is visible for (A) Na 1.7 and (B) Na 1.3 in the most apical MOE layer (arrowheads) and in axon bundles (arrows). (C,D) Higher magnifications of the MOE derived at different mouse ages stained with antibodies for (C) $\mathrm{Na}_{v} 1.7$ and (D) $\mathrm{Na}_{v} 1.3$. The confocal images show strongly stained OSN somata solely in the apical MOE. Somatic OSN staining is visible at embryonic day 18 (E18), P2, and P7, declines at about P14 and is nearly diminished at P21. Axon bundles stain early on (arrows) and increase in size with age in relation to epithelial thickness. Images are representatives of $(n \geq 2)$ mice at each age with $n \geq 10$ sections per mouse. Scale bars (A,B) $200 \mu m,(\mathbf{C}, \mathbf{D}) 20 \mu \mathrm{m}$.

immunohistochemistry. We analyzed MOE tissue sections derived from B6 or OMP-GFP mice at embryonic day 18 (E18), postnatal day 2 (P2), P7, P14 and P21 (Figures 4A-D). Surprisingly, between E18 and P7, we detected strong immunoreactivity for both $\mathrm{Na}_{\mathrm{v}} 1.3$ and $\mathrm{Na}_{\mathrm{v}} 1.7$ in OSNs that were primarily situated in the apical half of MOE (Figures 4C,D). The staining pattern at these ages was clearly different from that of adult tissue and showed robust labeling of OSN somata, dendrites and knobs (Figures 4C,D). The density of labeled OSN somata was relatively low at E18 but increased during development and reached its maximum at about P7, when immunoreactive OSN somata appeared tightly packed in the apical half of MOE (Figures 4C,D). At about P14, the somatic staining of OSNs started to disappear in the neuroepithelium lining the nasal septum and the dorsal roof, whereas olfactory turbinates maintained robust staining of somata at this age. At P21, the discerned staining for $\mathrm{Na}_{\mathrm{v}} 1.3$ and $\mathrm{Na}_{\mathrm{v}} 1.7$ in apical OSN somata diminished even in the olfactory turbinates (Figures 4C,D), and in adult mice pronounced somatic staining of OSN somata was absent. By contrast, immunoreactivity for $\mathrm{Na}_{\mathrm{v}} 1.3$ and $\mathrm{Na}_{\mathrm{v}} 1.7$ in OSN axon bundles was detectable at E18 and increased steadily with age and epithelial thickness (Figures 4C,D). Thus, the expression of $\mathrm{Na}_{\mathrm{v}} 1.3$ and $\mathrm{Na}_{\mathrm{v}} 1.7$ at somatic locations appears to be developmentally regulated and occurs in a transient manner, with a peak at P7, in contrast to the expression of these channels 

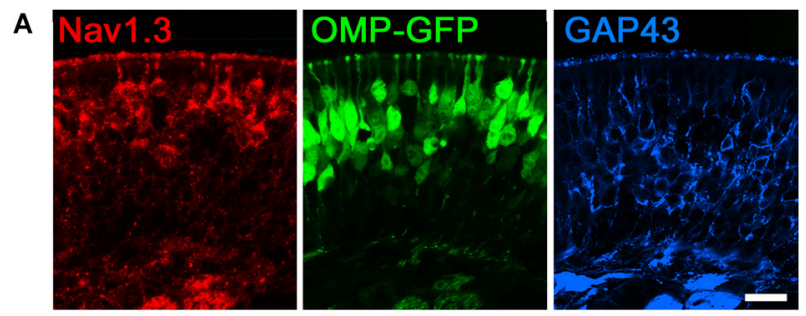

B

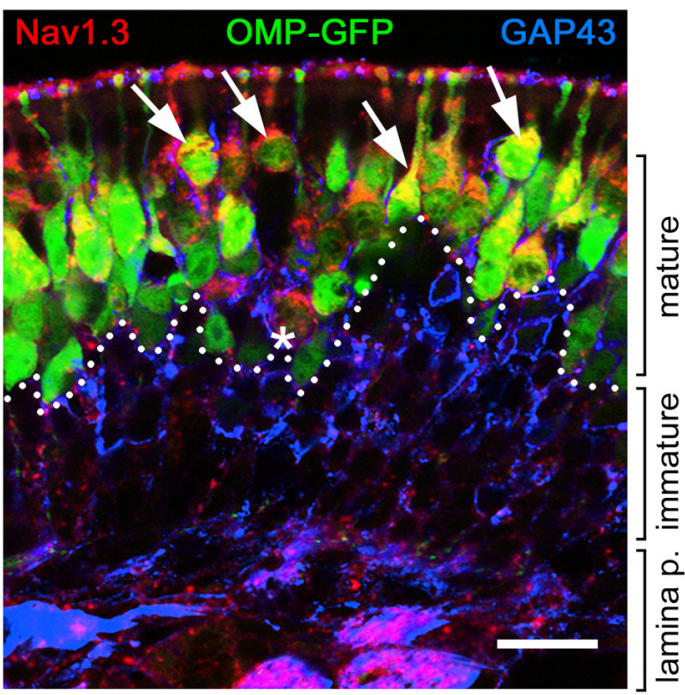

C
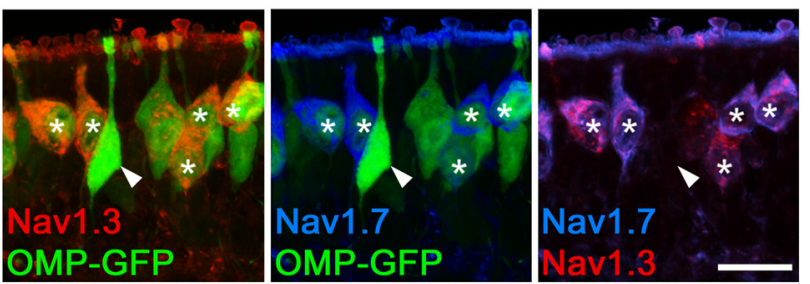

FIGURE 5 | Somatic expression of $\mathrm{Na}_{\mathrm{v}} 1.3$ and $\mathrm{Na}_{\mathrm{v}} 1.7$ occurs in mature OSNs. Colocalization of $\mathrm{Na}_{v} 1.3, \mathrm{GAP} 43$, and $\mathrm{Na}_{v} 1.7$ in the olfactory epithelium of a P7 OMP-GFP mouse (endogenous fluorescence, green). (A) Single fluorescence images for $\mathrm{Na}_{\mathrm{v}} 1.3$ (red), OMP-GFP (green), and GAP43 (blue). (B) Magnified merge of the images in (A) shows that $\mathrm{Na}_{v} 1.3$ colocalizes with OMP-GFP (arrows) in mature OSN somata located in the apical layer (dotted line). Occasionally, triple-labeled OSNs, positive for $\mathrm{Na}_{v}$ 1.3, OMP-GFP, and GAP43 were detected (asterisk). (C) Colocalization of $\mathrm{Na}_{v} 1.3$ (red) and $\mathrm{Na}_{v} 1.7$ (blue) in OMP-GFP+ OSNs (asterisks) intermingle with singly, OMP-GFP labeled OSNs (arrowhead). Images are representatives of $(n=2)$ mice with $n \geq 10$ sections per mouse. Scale bars, $20 \mu \mathrm{m}$.

in OSN axons which happens steadily over developmental time.

\section{Enhanced Somatic Expression of $\mathrm{Na}_{\mathrm{v}} 1.3$ and $\mathrm{Na}_{\mathrm{v}} 1.7$ in Mature OSNs of Juvenile Mice}

To gain further insight into the developmental regulation of $\mathrm{Na}_{\mathrm{v}}$ channel expression at OSN somata, we performed additional experiments in early postnatal mice, at P7. First, we used OMP-GFP mice and conducted a 3D reconstruction of confocal
Z-stacks to demonstrate that immunoreactivity for $\mathrm{Na}_{\mathrm{v}} 1.3$ and $\mathrm{Na}_{\mathrm{v}} 1.7$ in OSN somata colocalizes with endogenous GFP (Figures 5A-C). Thus, the transient expression of these two $\mathrm{Na}_{\mathrm{v}}$ channels is confined to mature, OMP-GFP ${ }^{+}$OSNs, although not all OMP-GFP ${ }^{+}$OSNs were immunoreactive for either $\mathrm{Na}_{\mathrm{v}} 1.3$ or $\mathrm{Na}_{\mathrm{v}} 1.7$ (Figures 5B,C). Second, we assessed colocalization of the growth-associated protein GAP43 (Verhaagen et al., 1989), a marker for immature OSNs, with either $\mathrm{Na}_{\mathrm{v}} 1.3$ or $\mathrm{Na}_{\mathrm{v}} 1.7$ in OMP-GFP mice (Figures 5A,B). These experiments revealed that GAP $43^{+}$OSNs of the basal MOE lacked immunoreactivity for both channel subtypes, consistent with our result that the somatic expression of $\mathrm{Na}_{\mathrm{v}} 1.3$ or $\mathrm{Na}_{\mathrm{v}} 1.7$ occurs in mature OSNs. Occasionally, we detected a triple-labeled OSN cell body, positive for OMP-GFP, GAP43 and either $\mathrm{Na}_{\mathrm{v}} 1.3$ or $\mathrm{Na}_{\mathrm{v}} 1.7$, indicating that these cells comprised an early mature OSN phenotype (Figure 5B). Third, we assessed whether $\mathrm{Na}_{\mathrm{v}} 1.3$ and $\mathrm{Na}_{\mathrm{V}} 1.7$ are expressed in the same OSNs. We performed doublelabeling experiments using antibodies raised in different species: a $\mathrm{Na}_{\mathrm{v}} 1.3$ antibody raised in goat and a rabbit antiserum for $\mathrm{Na}_{\mathrm{v}}$ 1.7. As illustrated by the confocal images depicted in Figure 5C, both $\mathrm{Na}_{\mathrm{v}} 1.3$ and $\mathrm{Na}_{\mathrm{v}} 1.7$ colocalize in the same OSN somata.

\section{Plasticity and Restoration of $\mathrm{Na}_{\mathrm{v}} \mathrm{1.3}$ and $\mathrm{Na}_{\mathrm{v}}$ 1.7 Expression in the Regenerating MOE}

Mammalian OSNs have the capacity to turn-over and regenerate throughout the animal's life span (Graziadei, G. A. and Graziadei, P. P. C., 1979; Graziadei, P. P. C. and Graziadei, G. A., 1979). Having shown that transient expression of $\mathrm{Na}_{\mathrm{v}} 1.3$ and $\mathrm{Na}_{\mathrm{v}} 1.7$ at OSN cell bodies coincides with a critical period of heightened plasticity during early postnatal maturation (Figures 4, 5), we next asked whether somatic expression of $\mathrm{Na}_{\mathrm{v}} 1.3$ and $\mathrm{Na}_{\mathrm{v}} 1.7$ can also be induced during regeneration and de novo OSN synthesis in the MOE. To test this, we performed peripheral deafferentation of the MOE through intranasal application of Triton X-100, an established method which induces severe chemical lesion of the neuroepithelium that is followed by tissue degeneration and subsequent regeneration from a pool of mitotic active stem cells located at the basal membrane (Nadi et al., 1981; Verhaagen et al., 1990).

We performed Triton X lesions using adult, 8-week-old OMP-GFP mice and analyzed regeneration of the MOE over a time course of $1,2,4,6,8$ and 10 weeks, respectively. One week after lesioning, the MOE was still severely damaged. Two weeks after lesion, the thickness of the MOE was recovered to about one third compared to unlesioned control tissue. At that time, we observed the first newly generated OMP-GFP ${ }^{+}$OSNs (Figures 6A,B) that were sparsely distributed in the regenerating MOE (Figures 6A,B). Small patches of epithelium remained intact in areas where lesions had been incomplete (Figure 6B). However, axon bundles in the underlying lamina propria had shrunk remarkably in the whole epithelium. Over the following weeks of recovery, the number of OMP-GFP ${ }^{+}$OSNs increased continuously and the epithelial thickness reached $\sim 90 \%$ of control levels by 8 weeks post-lesion (Figure 6C). 

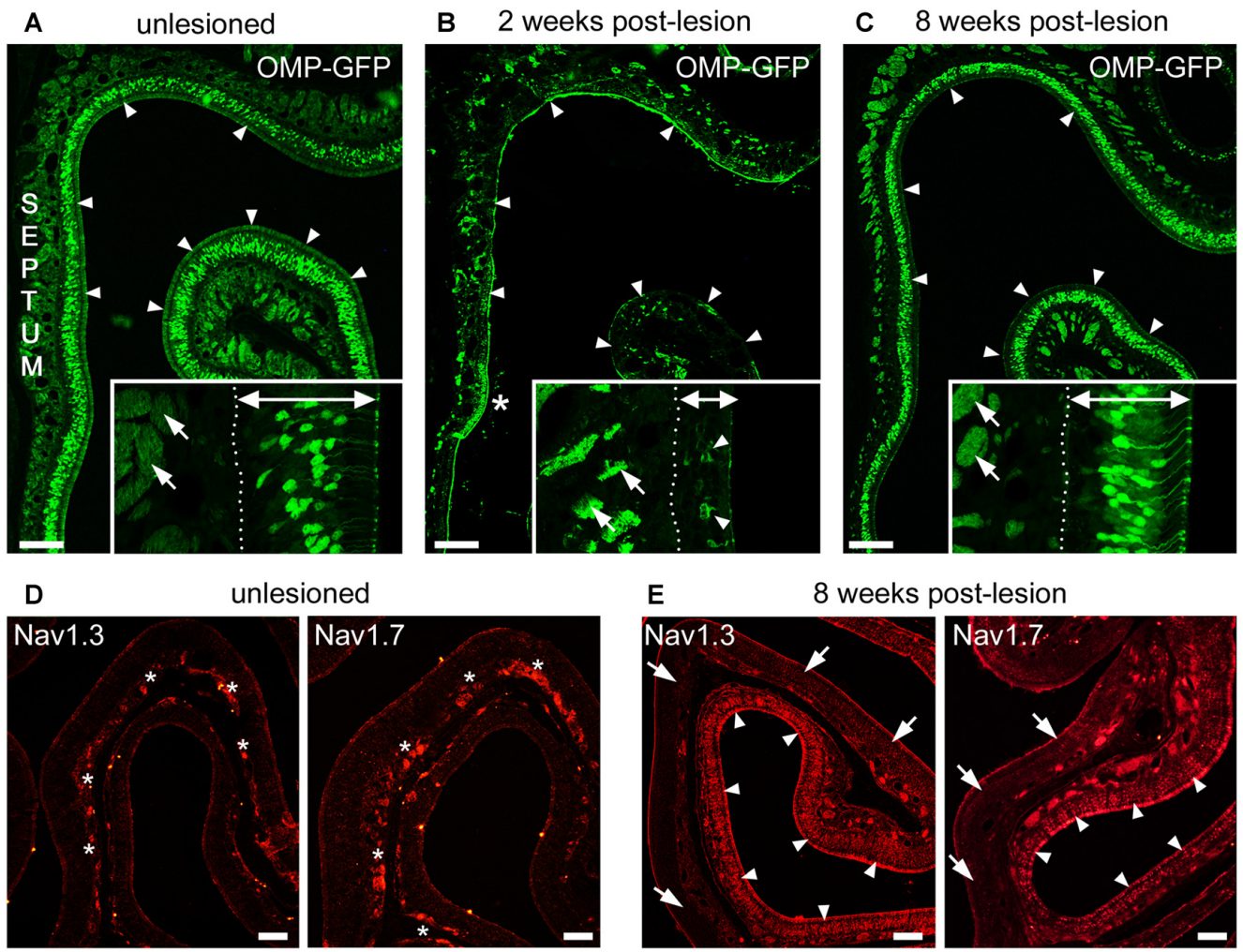

E
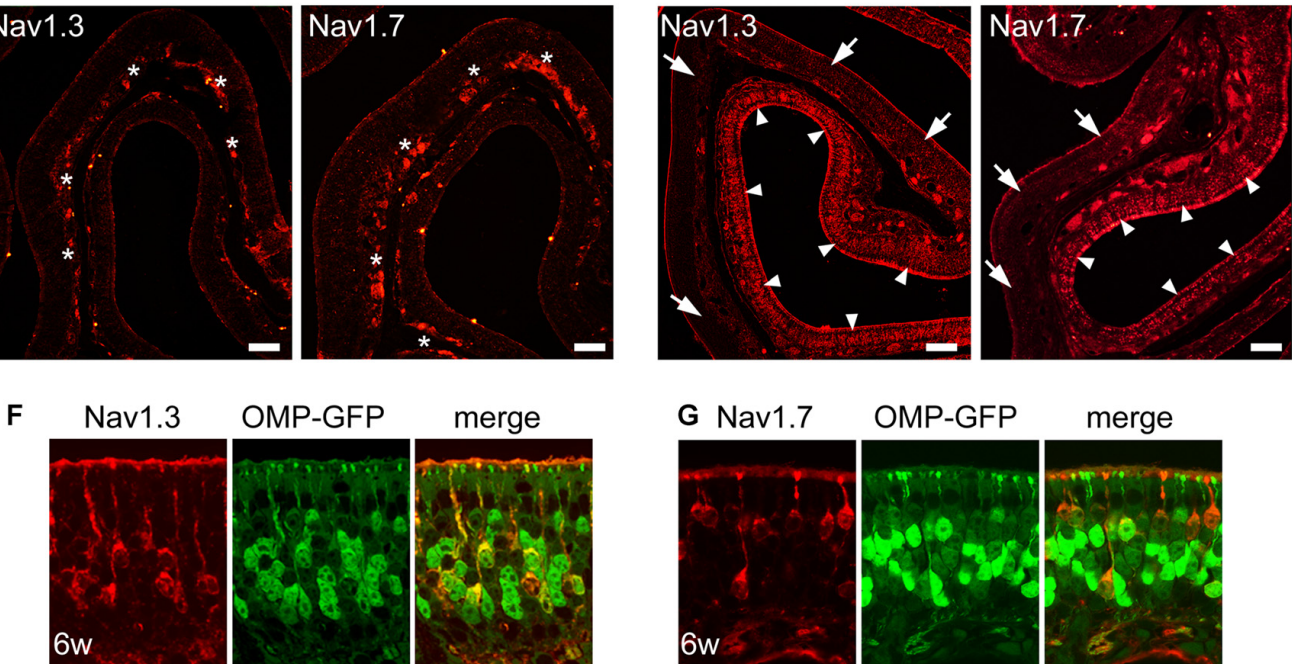

merge
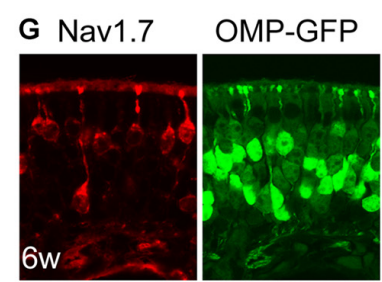

merge
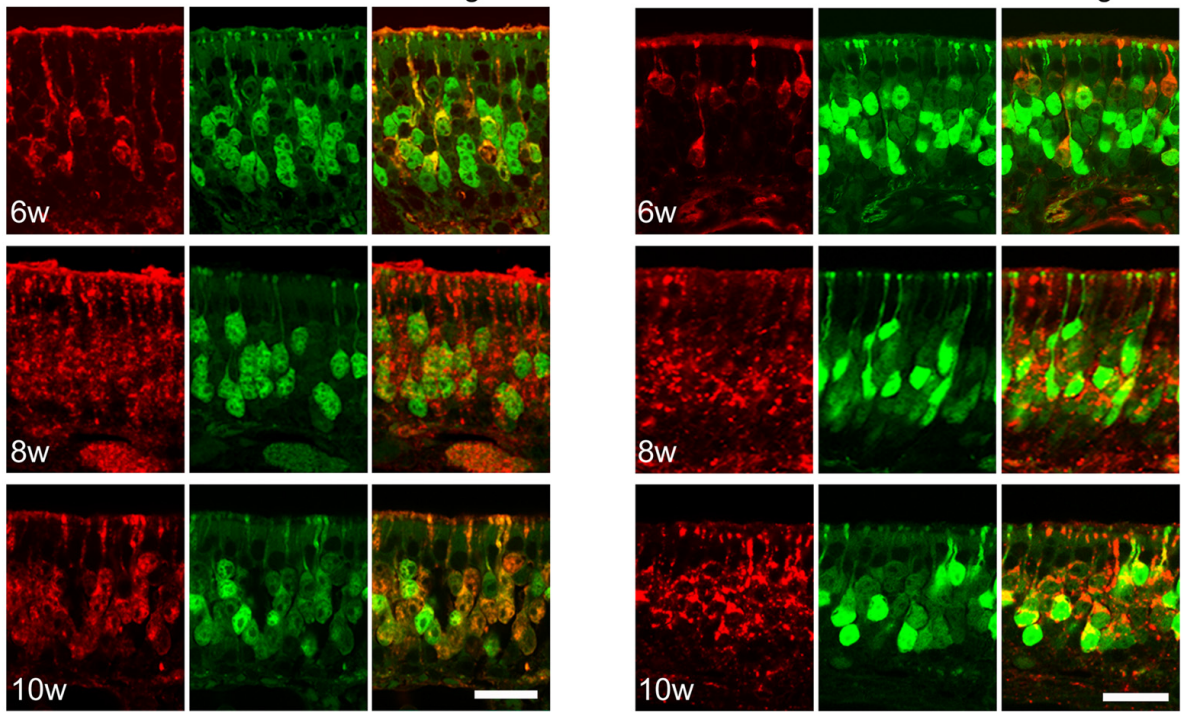

FIGURE 6 | Recovery of $\mathrm{Na}_{\mathrm{v}} 1.3$ and $\mathrm{Na}_{\mathrm{v}} 1.7$ expression in $\mathrm{OSN}$ somata during regeneration from chemical ablation. (A-C) Coronal MOE sections of the anterior left nasal cavity (septum to the left) of OMP-GFP mice. (A) Untreated control mice display OMP-GFP labeling of OSNs throughout the MOE (arrowheads). Inset magnification exemplifies regular thickness of axon bundles (arrows) and the MOE (double arrow, $80 \mu \mathrm{m}$ ). (B) Severely damaged MOE 2 weeks post-lesion. Small patch of unlesioned MOE at the septal wall (asterisk). The inset magnification depicts the reduced thickness of axon bundles (arrows) and the MOE (double arrow, $35 \mu \mathrm{m}) 2$ weeks post-lesion. Few newly generated OMP-GFP positive OSNs are visible (arrowheads). (C) The MOE has largely recovered 8 weeks post-lesion (arrowheads). The inset magnification shows that the thickness of axon bundles (arrows) and the MOE (double arrow, $70 \mu \mathrm{m}$ ) is increased. Basal membrane (dotted line). (D) Immunoreactivity for $\mathrm{Na}_{v} 1.3$ and $\mathrm{Na}_{\mathrm{v}} 1.7$ in the intact, unlesioned MOE shows strong labeling of axon bundles (asterisks). (E) Eight weeks post-lesion, tissue stretches with heavy immunolabeling for $\mathrm{Na}_{\mathrm{v}} 1.3$ and $\mathrm{Na}_{\mathrm{v}} 1.7$ in OSN somata (arrowheads) reside side-by-side with areas devoid of any somatic immunoreactivity (arrows). This pattern likely coincides with the different levels of initial damage yielding various levels of MOE regeneration. (F,G) Magnifications of the MOE at 6, 8, and 10 weeks post-lesion showing somatic staining for (F) $\mathrm{Na}_{\mathbf{v}} 1.3$ (red) and (G) $\mathrm{Na}_{\mathbf{v}} 1.7$ (red) colocalizing with OMP-GFP (green). Images are representatives of $(n=2)$ mice at each recovery time point with $n \geq 20$ sections per mouse. Scale bars (A-C) $200 \mu \mathrm{m},(\mathbf{D}, \mathbf{E}) 50 \mu \mathrm{m}$ (F,G) $20 \mu \mathrm{m}$. 

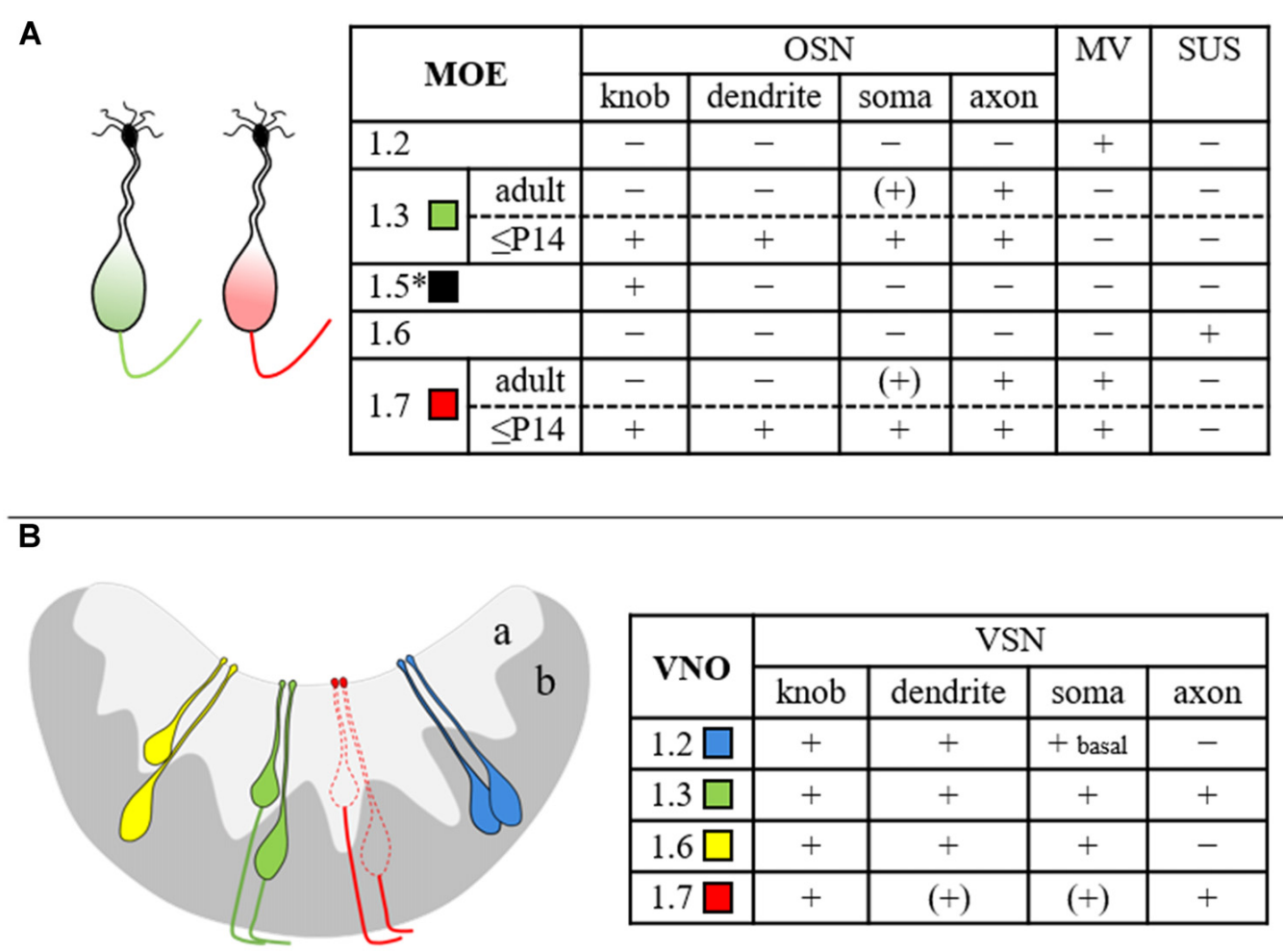

\begin{tabular}{|c|c|c|c|c|}
\hline \multirow{2}{*}{ VNO } & \multicolumn{4}{|c|}{ VSN } \\
\cline { 2 - 5 } & knob & dendrite & soma & axon \\
\hline $1.2 \square$ & + & + & + basal & - \\
\hline $1.3 \square$ & + & + & + & + \\
\hline $1.6 \square$ & + & + & + & - \\
\hline $1.7 \square$ & + & $(+)$ & $(+)$ & + \\
\hline
\end{tabular}

FIGURE 7 | Summary scheme depicting the cellular and subcellular distribution of various $\mathrm{Na}_{\mathbf{v}}$ channel isoforms in mouse MOE (A) and VNO (B). The drawings at the left illustrate the results obtained in this study and refer to the table at the right. Expression of Nav1.5 (asterisk) in OSN dendritic knobs (Frenz et al., 2014) has been included for completeness. The different $\mathrm{Na}_{v}$ channel subtypes are color-coded as indicated. The extent of immunoreactivity was categorized as + (present), - (absent), or (+) (close to detection threshold). MV, microvillar cells; OSN, olfactory sensory neuron; SUS, sustentacular cells; VSN, vomeronasal sensory neuron; a, apical VNO layer; b, basal VNO layer.

With respect to the expression of $\mathrm{Na}_{\mathrm{v}}$ channels during this regeneration process, at about 4 weeks post-lesion we occasionally detected immunostaining for $\mathrm{Na}_{\mathrm{v}} 1.3$ and $\mathrm{Na}_{\mathrm{v}} 1.7$ in single OSN somata, however, staining intensity was close to the detection threshold. At about 6 weeks post-lesion, immunoreactivity for both $\mathrm{Na}_{\mathrm{v}}$ channels was evident in a substantial number of OSNs exhibiting robust labeling of somata, dendrites, and dendritic knobs (Figures $\mathbf{6 E - G}$ ). The density of labeled OSNs increased towards 8 weeks post-lesion and robust somatic staining was still evident at 10 weeks postlesion. Colocalization with OMP-GFP showed that $\mathrm{Na}_{\mathrm{v}}$-positive OSNs also expressed GFP. Overall, the expression pattern closely resembled that of $\mathrm{P} 7$ mice during early postnatal development (for comparison, see Figure 4C). Thus, the expression of $\mathrm{Na}_{\mathrm{v}} 1.3$ and $\mathrm{Na}_{\mathrm{v}} 1.7$ in OSN somata appears to be highly plastic and seems to be linked to the establishment of the neuroepithelium during ontogeny and during regeneration following Triton X lesioning.

\section{DISCUSSION}

We have addressed the molecular basis of neuronal excitation in the mammalian olfactory system by investigating the organization and plasticity of $\mathrm{Na}_{\mathrm{v}}$ channel expression in the peripheral olfactory system of mice during adulthood and development of the MOE and VNO, and during regeneration of the MOE following chemical epithelial ablation. We used a combination of qPCR and immunohistochemistry to reveal fundamental similarities, but also important differences in the $\mathrm{Na}_{\mathrm{v}}$ repertoire employed by the two major olfactory subsystems, the MOE and the VNO. (1) PCR results show that $\mathrm{Na}_{\mathrm{v}} 1.7$ is the predominant isoform not only in the MOE but also in the VNO. (2) We provide immunohistochemical evidence that both $\mathrm{Na}_{\mathrm{v}} 1.3$ and $\mathrm{Na}_{\mathrm{v}} 1.7$ maybe fundamental for propagating action potentials in the two olfactory subsystems as they are primarily located to axons of sensory neurons. (3) We also show for the first time the complex organization of $\mathrm{Na}_{\mathrm{v}}$ channel expression in the VNO, which involves at least four different subtypes with different biophysical properties. In addition to $\mathrm{Na}_{\mathrm{V}} 1.3$ and $\mathrm{Na}_{\mathrm{V}} 1.7$ in VSN axons, we find robust expression of $\mathrm{Na}_{\mathrm{v}} 1.2$ and $\mathrm{Na}_{\mathrm{v}} 1.6$ in VSN somata. $\mathrm{Na}_{\mathrm{v}} 1.2$ only exists in VSNs located in the basal VNO layer and is expected to have a specific function in these neurons. (4) Finally, we show that $\mathrm{Na}_{\mathrm{v}} 1.3$ and $\mathrm{Na}_{\mathrm{v}} 1.7$ undergo changes in subcellular localization during the first weeks of development and during regeneration of the MOE following chemical lesion, which likely reflects specific physiological requirements associated with neuronal activity during periods of heightened plasticity. 


\section{$\mathrm{Na}_{\mathrm{v}}$ Channel mRNA Expression in MOE and VNO}

To address the question whether the MOE and the VNO share the same $\mathrm{Na}_{\mathrm{v}}$ channels or whether each system employs a unique set of channels, we first compared the expression profiles in the two tissues. Using real-time quantitative PCR, we identified six different $\mathrm{Na}_{\mathrm{v}}$ channel mRNAs in both MOE and VNO, demonstrating that these tissues share the same channels. Our results in the MOE are supported by previous reports that have identified these isoforms by RT-PCR (Weiss et al., 2011; Frenz et al., 2014) and deep RNA sequencing (Ibarra-Soria et al., 2014). In the VNO, Fieni et al. (2003) identified mRNAs encoding $\mathrm{Na}_{\mathrm{v}} 1.1$, $\mathrm{Na}_{\mathrm{v}} 1.2$, and $\mathrm{Na}_{\mathrm{v}} 1.3$. Our study confirms these isoforms and extends the VNO repertoire by the isoforms $\mathrm{Na}_{\mathrm{v}} 1.5$, $\mathrm{Na}_{\mathrm{v}} 1.6$, and $\mathrm{Na}_{\mathrm{v}} 1.7$. The frequency of individual isoforms was similar between the two olfactory subsystems, with $\mathrm{Na}_{\mathrm{v}} 1.7$ being the predominant isoform in the MOE and the VNO. These results are also consistent with the quantitative results from deep RNA sequencing (Ibarra-Soria et al., 2014). Despite these comparable mRNA repertoires, subsequent immunohistochemical localization analyses revealed specific differences and showed that the cellular and subcellular protein distribution of $\mathrm{Na}_{\mathrm{v}}$ channels is not identical in the two olfactory tissues (for summary see Figure 7).

\section{Sensory Neurons of the MOE Express $\mathrm{Na}_{\mathrm{v}} 1.3$ and $\mathrm{Na}_{\mathrm{v}} 1.7$}

In the MOE, we detected robust expression of $\mathrm{Na}_{\mathrm{v}} 1.3$ and $\mathrm{Na}_{\mathrm{v}} 1.7$ in OSN axons and substantially lower levels in OSN somata. This is consistent with previous results detecting both isoforms in OSN axons coursing the nerve layer of the main olfactory bulbs (Weiss et al., 2011). It was shown that $\mathrm{Na}_{\mathrm{v}} 1.7$ but not $\mathrm{Na}_{\mathrm{v}} 1.3$ is expressed in the axon terminals of OSNs, and that the unique localization of $\mathrm{Na}_{\mathrm{v}} 1.7$ may be critical for the synaptic transmission of olfactory information to the main olfactory bulb (Weiss et al., 2011; Zufall et al., 2012). A similar subcellular distribution has been shown for $\mathrm{Na}_{\mathrm{v}} 1.7$ in rat (Ahn et al., 2011). The redundancy of $\mathrm{Na}_{\mathrm{v}} 1.3$ and $\mathrm{Na}_{\mathrm{v}} 1.7$ in OSN axons implies that the two channel subtypes likely function in a coordinated manner in the generation and propagation of action potentials. $\mathrm{Na}_{\mathrm{v}} 1.3$ and $\mathrm{Na}_{\mathrm{v}} 1.7$ display similar biophysical properties, including fast activation and inactivation kinetics and a slow closed-state inactivation that enables inward currents even in response to weak depolarizations (Klugbauer et al., 1995; Cummins et al., 2001; Herzog et al., 2003). However, $\mathrm{Na}_{\mathrm{v}} 1.3$ recovers three times faster from inactivation than $\mathrm{Na}_{\mathrm{v}} 1.7$ (Cummins et al., 2001). It is therefore conceivable that $\mathrm{Na}_{\mathrm{v}} 1.3$ bypasses the longer recovery times of $\mathrm{Na}_{\mathrm{v}} 1.7$ to maintain firing at high frequency after odor-induced depolarization.

We did not detect $\mathrm{Na}_{\mathrm{v}} 1.3$ or $\mathrm{Na}_{\mathrm{v}} 1.7$ in dendritic endings of OSNs. This location is occupied by $\mathrm{Na}_{\mathrm{v}} 1.5$, a subtype that has been shown recently to contribute to spontaneous OSN activity (Frenz et al., 2014) and may transduce small, odorantevoked receptor potentials into action potential firing (Dionne,
2016). Together, these results suggest that OSNs employ at least three different $\mathrm{Na}_{\mathrm{v}}$ channel subtypes for action potential generation, propagation, and signal transmission $-\mathrm{Na}_{\mathrm{v}} 1.5$ in dendritic knobs, $\mathrm{Na}_{\mathrm{v}} 1.3$ and $\mathrm{Na}_{\mathrm{v}} 1.7$ in somata and axons, and $\mathrm{Na}_{\mathrm{v}} 1.7$ in axon terminals of OSNs.

\section{Sensory Neurons of the VNO Employ Four Different $\mathrm{Na}_{\mathrm{v}}$ Channel Subtypes}

Only limited information has been available on the molecular identity of the $\mathrm{Na}_{\mathrm{v}}$ channel subtypes employed by the VNO. Thus far, only one study has demonstrated expression of the subtype $\mathrm{Na}_{\mathrm{v}} 1.3$ in $\mathrm{VNO}$ tissue sections using in situ hybridization (Fieni et al., 2003). We now demonstrate that at least four $\mathrm{Na}_{\mathrm{v}}$ channel subtypes with different biophysical properties are expressed in sensory neurons of the VNO. The four channels exhibit differential but not exclusive expression in specific subcellular VSN compartments and display onset of expression during the first postnatal week of life (Figure 3). Consistent with their presumptive function in action potential generation and impulse propagation in the vomeronasal system, we identified $\mathrm{Na}_{\mathrm{v}} 1.2, \mathrm{Na}_{\mathrm{v}} 1.3, \mathrm{Na}_{\mathrm{v}} 1.6$, and low levels of $\mathrm{Na}_{\mathrm{v}} 1.7$ in somata and $\mathrm{Na}_{\mathrm{v}} 1.3$ and $\mathrm{Na}_{\mathrm{v}} 1.7$ in axons of VSNs (Figure 3), respectively. $\mathrm{Na}_{\mathrm{v}} 1.6$ expression was stronger in VSN somata of the basal VNO layer than in the apical layer, whereas $\mathrm{Na}_{\mathrm{V}} 1.3$ was uniformly expressed in all VSNs. Most intriguingly, $\mathrm{Na}_{\mathrm{v}} 1.2$ was limited to VSN somata of the basal layer, suggesting that this channel may play a special role in these VSNs. This is in agreement with earlier reports demonstrating that the electrophysiological characteristics of sodium currents differ in apical vs. basal VSNs (Liman and Corey, 1996; Fieni et al., 2003; Ukhanov et al., 2007; Ackels et al., 2014). $\mathrm{Na}_{\mathrm{v}}$ currents of basal VSNs were shown to be smaller using a dissociated VNO preparation (Fieni et al., 2003). Using an intact VNO slice preparation and genetically-identified VSNs, VSNs of the basal VNO layer were shown to exhibit larger currents and to produce faster and larger spikes than apical VSNs (Ukhanov et al., 2007). Interestingly, $\mathrm{Na}_{\mathrm{v}} 1.2$ is characterized by fast inactivation kinetics and by generating repetitive action potential firing (Catterall et al., 2005), which could explain that basal VSNs are capable to maintain persistent firing for extended periods of time (Ukhanov et al., 2007). Thus, the coordinated action of three different $\mathrm{Na}_{\mathrm{v}}$ channels in basal VSNs and two different $\mathrm{Na}_{\mathrm{v}}$ channels in apical VSNs enable the finelytuned control of action potential firing in the respective VNO layers.

Furthermore, the robust expression of $\mathrm{Na}_{\mathrm{v}} 1.3$ and $\mathrm{Na}_{\mathrm{v}} 1.7$ we observed in VSN axons parallels our results in the MOE and suggests an analogous function of these $\mathrm{Na}_{\mathrm{V}}$ channels in the accessory olfactory system. We propose that $\mathrm{Na}_{\mathrm{v}} 1.3$ and $\mathrm{Na}_{\mathrm{v}} 1.7$ represent fundamental subtypes in the conduction of electrical signaling in both VSNs and OSNs. Moreover, consistent with the recent observation that $\mathrm{Na}_{\mathrm{v}} 1.7$ is expressed in the nerve and glomerular layers of the accessory olfactory bulb in rat (Rupasinghe et al., 2012) and our unpublished results in mouse, we suggest that similar to the MOE (Weiss et al., 2011), 
$\mathrm{Na}_{\mathrm{v}} 1.7$ may play an essential role in olfactory signal transmission at the first synapse of the AOB.

\section{Special Roles for $\mathrm{Na}_{\mathrm{v}} 1.3$ and $\mathrm{Na}_{\mathrm{v}} 1.7$ during MOE Development and Regeneration}

The generation of neural activity through action potentials is a major determinant in the regulation of development and plasticity of the nervous system (Hensch, 2004; Holtmaat and Svoboda, 2009). Having shown that $\mathrm{Na}_{\mathrm{v}} 1.3$ and $\mathrm{Na}_{\mathrm{v}} 1.7$ represent fundamental $\mathrm{Na}_{\mathrm{v}}$ channels for action potential propagation in the adult, we focused on the developmental expression of the two $\mathrm{Na}_{\mathrm{v}}$ channels in the MOE. Our results show that the subcellular distribution of $\mathrm{Na}_{\mathrm{v}}$ channels in young mice was remarkably different from adults. Between E18 and P14, expression of $\mathrm{Na}_{\mathrm{v}} 1.3$ and $\mathrm{Na}_{\mathrm{v}} 1.7$ was pronounced in somata, dendrites, and knobs of OSNs and was limited to mature, OMP-positive OSNs. Somatic expression peaked at about P7 and subsided within the following 2 weeks to the low levels observed in the adult, while axonal expression was maintained from E18 on. This differential, time-dependent expression of $\mathrm{Na}_{\mathrm{v}}$ channels in OSN compartments coincides with a critical period of heightened plasticity during early postnatal life (Hensch, 2004) and is likely to meet specific requirements associated with increased neuronal activity. Electrical activity promotes axon outgrowth (Mobley et al., 2010), olfactory synapse formation (Cheetham et al., 2016), and establishment of a topographic map in the olfactory bulb (Yu et al., 2004; Ma et al., 2014). Furthermore, silencing spontaneous activity delays axonal outgrowth (Mobley et al., 2010) and precise axonal targeting to specific glomeruli in the olfactory bulb (Yu et al., 2004; Ma et al., 2014; Tsai and Barnea, 2014). Interestingly, the time course of somatic $\mathrm{Na}_{\mathrm{v}}$ expression we observed in this study coincides with that of olfactory synapse maturation and refinement. Synapse formation between OSNs and postsynaptic mitral/tufted cells in the main olfactory bulbs starts at about embryonic day 15 and continues throughout life (Hinds and Hinds, 1976; Blanchart et al., 2008). Exuberant axonal projections and synapses peak at about postnatal day 8 and are eliminated towards postnatal day 20 (Marcucci et al., 2011). Thus, it is conceivable that $\mathrm{Na}_{\mathrm{v}}$-dependent electrical activity may contribute to refinement or strengthening of olfactory synapses formed during early postnatal development. Furthermore, we showed that expression of $\mathrm{Na}_{\mathrm{v}} 1.3$ and $\mathrm{Na}_{\mathrm{v}} 1.7$ in OSN somata was confined to mature, OMP-positive somata (Figure 5), which is consistent with the observation that the onset of OMP expression closely associates with synapse formation (Graziadei et al., 1978; Farbman and Margolis, 1980; Rodriguez-Gil et al., 2015; Cheetham et al., 2016). Thus, somatic $\mathrm{Na}_{\mathrm{v}}$ expression in OSNs is turned-off following synapse refinement whereas axonal expression of $\mathrm{Na}_{\mathrm{v}}$ channels is maintained. However, at the current state we cannot exclude the possibility that somatic $\mathrm{Na}_{\mathrm{v}}$ expression is linked to other developmental processes, as well.

In contrast to embryonic and early postnatal mice, we never detected such striking $\mathrm{Na}_{\mathrm{v}}$ immunoreactivity in OSN somata of the adult MOE, as might be expected from OSNs that emerge during adult neurogenesis. This observation is in line with the idea that mechanisms regulating embryonic, juvenile, and adult neurogenesis are overlapping but not identical
(Brann and Firestein, 2014; Ma et al., 2014). Adult born OSNs differentiate in the context of an established olfactory network in which somatic $\mathrm{Na}_{\mathrm{v}}$ expression may be dispensable. To test whether the transient expression of $\mathrm{Na}_{\mathrm{v}}$ channels in OSN somata can be restored during regeneration of the MOE, we used Triton $\mathrm{X}$ to reversibly lesion the MOE and to track $\mathrm{Na}_{\mathrm{v}}$ channel expression during de novo synthesis of OSNs. Unlike other sensory systems, the olfactory system has a remarkable regenerative capacity due to a pool of stem cells located at the basal lamina of the MOE (Graziadei, G. A. and Graziadei, P. P. C., 1979; Graziadei, P. P. C. and Graziadei, G. A., 1979). Consistent with earlier reports (Nadi et al., 1981; Verhaagen et al., 1990), our results show that after massive degeneration of the MOE during the first week post-lesion, newly generated, OMP-positive OSNs emerge within 2 weeks post-lesion. About 6 weeks post-lesion, we detected robust immunostaining for $\mathrm{Na}_{\mathrm{v}} 1.3$ and $\mathrm{Na}_{\mathrm{v}} 1.7$ in OSN somata (Figure 6), which was similar to the expression pattern we observed during late embryonic and early postnatal MOE development.

Thus, the somatic expression of $\mathrm{Na}_{\mathrm{v}} 1.3$ and $\mathrm{Na}_{\mathrm{v}} 1.7$ in OSNs appears to be highly plastic which is consistent with specific roles for the two $\mathrm{Na}_{\mathrm{v}}$ channels. Although lesion-evoked MOE regeneration in adult mice is not simply a recapitulation of ontogeny, our data suggest that somatic expression of $\mathrm{Na}_{\mathrm{v}} 1.3$ and $\mathrm{Na}_{\mathrm{v}} 1.7$ might be part of a program involving increased electrical activity during the initial maturation process and during recovery from injury of the olfactory epithelium.

In summary, we have provided a systematic analysis of the expression of $\mathrm{Na}_{\mathrm{v}}$ channel isoforms in the peripheral mammalian olfactory system. These experiments reveal complex patterns and highly specific differences of $\mathrm{Na}_{\mathrm{v}}$ channel expression between the MOE and VNO, and during periods of high plasticity of these tissues. Experiments using conditional mutations in these $\mathrm{Na}_{\mathrm{v}}$ channel subunits, akin to those used for understanding the role of $\mathrm{Na}_{\mathrm{v}} 1.7$ (Weiss et al., 2011), will be required to analyze the precise functional contribution of each these ion channels to olfactory performance.

\section{AUTHOR CONTRIBUTIONS}

MP: study concept; FB, SK and MP: data acquisition (immunohistochemistry, confocal microscopy; FB (Triton- $\mathrm{X}$ lesion), BB (qPCR)). FB, BB, SK, MP and FZ: data interpretation; MP: figure preparation; MP and FZ: drafting of the manuscript; FB, BB: revision of the manuscript. All authors take responsibility for data integrity and data analysis accuracy.

\section{FUNDING}

This work was supported by Deutsche Forschungsgemeinschaft (DFG) grants PY 90/1-1 (to MP) and SFB 894 (to FZ).

\section{ACKNOWLEDGMENTS}

We thank Jan Weiss for valuable discussions of this project and Petra Hammes for technical assistance. 


\section{REFERENCES}

Ackels, T., von der Weid, B., Rodriguez, I., and Spehr, M. (2014). Physiological characterization of formyl peptide receptor expressing cells in the mouse vomeronasal organ. Front. Neuroanat. 8:134. doi: 10.3389/fnana.2014. 00134

Ahn, H.-S., Black, J. A., Zhao, P., Tyrrell, L., Waxman, S. G., and Dib-Hajj, S. D. (2011). $\mathrm{Na}_{\mathrm{v}} 1.7$ is the predominant sodium channel in rodent olfactory sensory neurons. Mol. Pain 7:32. doi: 10.1186/1744-8069-7-32

Blanchart, A., Romaguera, M., García-Verdugo, J. M., de Carlos, J. A., and LópezMascaraque, L. (2008). Synaptogenesis in the mouse olfactory bulb during glomerulus development. Eur. J. Neurosci. 27, 2838-2846. doi: 10.1111/j.14609568.2008.06283.x

Brann, J. H., and Firestein, S. J. (2014). A lifetime of neurogenesis in the olfactory system. Front. Neurosci. 8:182. doi: 10.3389/fnins.2014.00182

Bustin, S. A., Benes, V., Garson, J. A., Hellemans, J., Huggett, J., Kubista, M., et al. (2009). The MIQE guidelines: minimum information for publication of quantitative real-time PCR experiments. Clin. Chem. 55, 611-622. doi: 10.1373/clinchem.2008.112797

Catterall, W. A., Goldin, A. L., and Waxman, S. G. (2005). International Union of pharmacology. XLVII. Nomenclature and structure-function relationships of voltage-gated sodium channels. Pharmacol. Rev. 57, 397-409. doi: 10.1124/pr. 57.4 .4

Cheetham, C. E., Park, U., and Belluscio, L. (2016). Rapid and continuous activity-dependent plasticity of olfactory sensory input. Nat. Commun. 7:10729. doi: 10.1038/ncomms10729

Cummins, T. R., Aglieco, F., Renganathan, M., Herzog, R. I., Dib-Hajj, S. D., and Waxman, S. G. (2001). $\mathrm{Na}_{\mathrm{v}} 1.3$ sodium channels: rapid repriming and slow closed-state inactivation display quantitative differences after expression in a mammalian cell line and in spinal sensory neurons. J. Neurosci. 21, 5952-5961.

Dib-Hajj, S. D., Cummins, T. R., Black, J. A., and Waxman, S. G. (2010). Sodium channels in normal and pathological pain. Annu. Rev. Neurosci. 33, 325-347. doi: 10.1146/annurev-neuro-060909-153234

Dionne, V. E. (2016). Spontaneously active $\mathrm{Na}_{\mathrm{v}} 1.5$ sodium channels may underlie odor sensitivity. J. Neurophysiol. 116, 776-783. doi: 10.1152/jn.00114.2016

Elsaesser, R., and Paysan, J. (2005). Morituri te salutant? Olfactory signal transduction and the role of phosphoinositides. J. Neurocytol. 34, 97-116. doi: $10.1007 / \mathrm{s} 11068-005-5050-\mathrm{Z}$

Farbman, A. I. (Ed.). (1992). Cell Biology of Olfaction. New York, NY: Cambridge University Press.

Farbman, A. I., and Margolis, F. L. (1980). Olfactory marker protein during ontogeny: immunohistochemical localization. Dev. Biol. 74, 205-215. doi: 10.1016/0012-1606(80)90062-7

Fieni, F., Ghiaroni, V., Tirindelli, R., Pietra, P., and Bigiani, A. (2003). Apical and basal neurones isolated from the mouse vomeronasal organ differ for voltagedependent currents. J. Physiol. 552, 425-436. doi: 10.1113/jphysiol.2003. 052035

Firestein, S. (2001). How the olfactory system makes sense of scents. Nature 413, 211-218. doi: $10.1038 / 35093026$

Frenz, C. T., Hansen, A., Dupuis, N. D., Shultz, N., Levinson, S. R., Finger, T. E., et al. (2014). $\mathrm{Na}_{\mathrm{v}} 1.5$ sodium channel window currents contribute to spontaneous firing in olfactory sensory neurons. J. Neurophysiol. 112, 1091-1104. doi: 10.1152/jn.00154.2014

Gao, N., Lu, M., Echeverri, F., Laita, B., Kalabat, D., Williams, M. E., et al. (2009). Voltage-gated sodium channels in taste bud cells. BMC Neurosci. 10:20. doi: 10.1186/1471-2202-10-20

Goldin, A. L., Barchi, R. L., Caldwell, J. H., Hofmann, F., Howe, J. R., Hunter, J. C., et al. (2000). Nomenclature of voltage-gated sodium channels. Neuron 28, 365-368. doi: 10.1016/S0896-6273(00)00116-1

Graziadei, G. A., and Graziadei, P. P. C. (1979). Neurogenesis and neuron regeneration in the olfactory system of mammals. II. Degeneration and reconstitution of the olfactory sensory neurons after axotomy. J. Neurocytol. 8, 197-213. doi: 10.1007/bf01175561

Graziadei, P. P. C., and Graziadei, G. A. (1979). Neurogenesis and neuron regeneration in the olfactory system of mammals. I. Morphological aspects of differentiation and structural organization of the olfactory sensory neurons. J. Neurocytol. 8, 1-18. doi: 10.1007/bf01206454
Graziadei, P. P. C., Levine, R. R., and Graziadei, G. A. (1978). Regeneration of olfactory axons and synapse formation in the forebrain after bulbectomy in neonatal mice. Proc. Natl. Acad. Sci. U S A 75, 5230-5234. doi: 10.1073/pnas. 75.10 .5230

Hensch, T. K. (2004). Critical period regulation. Annu. Rev. Neurosci. 27, 549-579. doi: 10.1146/annurev.neuro.27.070203.144327

Herzog, R. I., Cummins, T. R., Ghassemi, F., Dib-Hajj, S. D., and Waxman, S. G. (2003). Distinct repriming and closed-state inactivation kinetics of $\mathrm{Na}_{\mathrm{v}} 1.6$ and $\mathrm{Na}_{\mathrm{V}} 1.7$ sodium channels in mouse spinal sensory neurons. J. Physiol. 551, 741-750. doi: 10.1113/jphysiol.2003.047357

Hinds, J. W., and Hinds, P. L. (1976). Synapse formation in the mouse olfactory bulb. I. Quantitative studies. J. Comp. Neurol. 169, 15-40. doi: 10.1002/cne. 901690103

Holtmaat, A., and Svoboda, K. (2009). Experience-dependent structural synaptic plasticity in the mammalian brain. Nat. Rev. Neurosci. 10, 647-658. doi: 10.1038/nrn2699

Ibarra-Soria, X., Levitin, M. O., Saraiva, L. R., and Logan, D. W. (2014). The olfactory transcriptomes of mice. PLoS Genet. 10:e1004593. doi: 10.1371/journal.pgen.1004593

Kim, C. H., Oh, Y., Chung, J. M., and Chung, K. (2002). Changes in three subtypes of tetrodotoxin sensitive sodium channel expression in the axotomized dorsal root ganglion in the rat. Neurosci. Lett. 323, 125-128. doi: 10.1016/s03043940(02)00127-1

Kleene, S. J. (2008). The electrochemical basis of odor transduction in vertebrate olfactory cilia. Chem. Senses 33, 839-859. doi: 10.1093/chemse/bjn048

Klugbauer, N., Lacinova, L., Flockerzi, V., and Hofmann, F. (1995). Structure and functional expression of a new member of the tetrodotoxin-sensitive voltageactivated sodium channel family from human neuroendocrine cells. EMBO J. 14, 1084-1090.

Liman, E. R., and Corey, D. P. (1996). Electrophysiological characterization of chemosensory neurons from the mouse vomeronasal organ. J. Neurosci. 16, 4625-4637.

Ma, L., Wu, Y., Qiu, Q., Scheerer, H., Moran, A., and Yu, C. R. (2014). A developmental switch of axon targeting in the continuously regenerating mouse olfactory system. Science 344, 194-197. doi: 10.1126/science. 1248805

Marcucci, F., Maier-Balough, E., Zou, D. J., and Firestein, S. (2011). Exuberant growth and synapse formation of olfactory sensory neuron axonal arborizations. J. Comp. Neurol. 519, 3713-3726. doi: 10.1002/cne.22684

Martini, S., Silvotti, L., Shirazi, A., Ryba, N. J., and Tirindelli, R. (2001). Co-expression of putative pheromone receptors in the sensory neurons of the vomeronasal organ. J. Neurosci. 21, 843-848.

Mobley, A. S., Miller, A. M., Araneda, R. C., Maurer, L. R., Muller, F., and Greer, C. A. (2010). Hyperpolarization-activated cyclic nucleotide-gated channels in olfactory sensory neurons regulate axon extension and glomerular formation. J. Neurosci. 30, 16498-16508. doi: 10.1523/JNEUROSCI.4225-10. 2010

Munger, S. D., Leinders-Zufall, T., and Zufall, F. (2009). Subsystem organization of the mammalian sense of smell. Annu. Rev. Physiol. 71, 115-140. doi: 10.1146/annurev.physiol.70.113006.100608

Nadi, N. S., Head, R., Grillo, M., Hempstead, J., Grannot-Reisfeld, N., and Margolis, F. L. (1981). Chemical deafferentation of the olfactory bulb: plasticity of the levels of tyrosine hydroxylase, dopamine and norepinephrine. Brain Res. 213, 365-377. doi: 10.1016/0006-8993(81) 90241-9

Pifferi, S., Menini, A., and Kurahashi, T. (2010). "Signal transduction in vertebrate olfactory cilia," in The Neurobiology of Olfaction, ed. A. Menini (Boca Raton, FL: CRC Press/Taylor and Francis), 203-224.

Potter, S. M., Zheng, C., Koos, D. S., Feinstein, P., Fraser, S. E., and Mombaerts, P. (2001). Structure and emergence of specific olfactory glomeruli in the mouse. J. Neurosci. 21, 9713-9723.

Rodriguez-Gil, D. J., Bartel, D. L., Jaspers, A. W., Mobley, A. S., Imamura, F., and Greer, C. A. (2015). Odorant receptors regulate the final glomerular coalescence of olfactory sensory neuron axons. Proc. Natl. Acad. Sci. U S A 112 , 5821-5826. doi: 10.1073/pnas.1417955112

Rupasinghe, D. B., Knapp, O., Blomster, L. V., Schmid, A. B., Adams, D. J., King, G. F., et al. (2012). Localization of $\mathrm{Na}_{\mathrm{v}} 1.7$ in the normal and injured 
rodent olfactory system indicates a critical role in olfaction, pheromone sensing and immune function. Channels (Austin) 6, 103-110. doi: 10.4161/chan. 19484

Sage, D., Salin, P., Alcaraz, G., Castets, F., Giraud, P., Crest, M., et al. (2007). $\mathrm{Na}_{\mathrm{V}} 1.7$ and $\mathrm{Na}_{\mathrm{v}} 1.3$ are the only tetrodotoxin-sensitive sodium channels expressed by the adult guinea pig enteric nervous system. J. Comp. Neurol. 504, 363-378. doi: 10.1002/cne.21450

Sammeta, N., Yu, T. T., Bose, S. C., and McClintock, T. S. (2007). Mouse olfactory sensory neurons express 10,000 genes. J. Comp. Neurol. 502, 1138-1156. doi: $10.1002 /$ cne. 21365

Shepherd, G. M., Chen, W. R., and Greer, C. A. (2004). "Olfactory bulb," in The Synaptic Organization of the Brain, 5 Edn. ed. G. M. Shepherd (New York, NY: Oxford University Press), 165-216.

Tsai, L., and Barnea, G. (2014). A critical period defined by axon-targeting mechanisms in the murine olfactory bulb. Science 344, 197-200. doi: $10.1126 /$ science. 1248806

Ukhanov, K., Leinders-Zufall, T., and Zufall, F. (2007). Patch-clamp analysis of gene-targeted vomeronasal neurons expressing a defined V1r or V2r receptor: ionic mechanisms underlying persistent firing. J. Neurophysiol. 98, 2357-2369. doi: $10.1152 /$ jn.00642.2007

Verhaagen, J., Oestreicher, A. B., Gispen, W. H., and Margolis, F. L. (1989). The expression of the growth associated protein B50/GAP43 in the olfactory system of neonatal and adult rats. J. Neurosci. 9, 683-691.

Verhaagen, J., Oestreicher, A. B., Grillo, M., Khew-Goodall, Y. S., Gispen, W. H., and Margolis, F. L. (1990). Neuroplasticity in the olfactory system: differential effects of central and peripheral lesions of the primary olfactory pathway on the expression of B-50/GAP43 and the olfactory marker protein. J. Neurosci. Res. 26, 31-44. doi: 10.1002/jnr.490260105

Wachowiak, M., and Shipley, M. T. (2006). Coding and synaptic processing of sensory information in the glomerular layer of the olfactory bulb. Semin. Cell Dev. Biol. 17, 411-423. doi: 10.1016/j.semcdb.2006.04.007
Waxman, S. G., Kocsis, J. D., and Black, J. A. (1994). Type III sodium channel mRNA is expressed in embryonic but not adult spinal sensory neurons and is reexpressed following axotomy. J. Neurophysiol. 72, 466-470.

Weiss, J., Pyrski, M., Jacobi, E., Bufe, B., Willnecker, V., Schick, B., et al. (2011). Loss-of-function mutations in sodium channel $\mathrm{Na}_{\mathrm{v}} 1.7$ cause anosmia. Nature 472, 186-190. doi: 10.1038/nature09975

Yu, C. R., Power, J., Barnea, G., O’Donnell, S., Brown, H. E., Osborne, J., et al. (2004). Spontaneous neural activity is required for the establishment and maintenance of the olfactory sensory map. Neuron 42, 553-566. doi: 10.1016/s0896-6273(04)00224-7

Zufall, F., and Munger, S. (Eds). (2016). Chemosensory Transduction. The Detection of Odors, Tastes and Other Chemostimuli. Cambridge, MA: Academic Press.

Zufall, F., Pyrski, M., Weiss, J., and Leinders-Zufall, T. (2012). Link between pain and olfaction in an inherited sodium channelopathy. Arch. Neurol. 69, 1119-1123. doi: 10.1001/archneurol.2012.21

Conflict of Interest Statement: The authors declare that the research was conducted in the absence of any commercial or financial relationships that could be construed as a potential conflict of interest.

The handling Editor declared a past co-authorship with one of the authors MP and the handling Editor states that the process met the standards of a fair and objective review.

Copyright (C) 2017 Bolz, Kasper, Bufe, Zufall and Pyrski. This is an open-access article distributed under the terms of the Creative Commons Attribution License (CC BY). The use, distribution and reproduction in other forums is permitted, provided the original author(s) or licensor are credited and that the original publication in this journal is cited, in accordance with accepted academic practice. No use, distribution or reproduction is permitted which does not comply with these terms. 